\title{
Cheese whey valorisation: Production of valuable gaseous and liquid chemicals from lactose by aqueous phase reforming
}

\author{
J. Remón, J. Ruiz, M. Oliva, L. García , J. Arauzo
}

Thermochemical Processes Group (GPT), Aragón Institute for Engineering Research (I3A), Universidad de Zaragoza. Mariano Esquillor s/n, E-50018 Zaragoza, Spain. *Corresponding author. Tel: +34 976 762194; Fax.: +34 976 761879; e-mail: luciag@unizar.es

\section{ABSTRACT}

Cheese effluent management has become an important issue owing to its high

biochemical oxygen demand and chemical oxygen demand values. Given this scenario, this work addresses the valorisation of lactose (the largest organic constituent of this waste) by aqueous phase reforming, analysing the influence of the most important operating variables (temperature, pressure, lactose concentration and mass of catalyst/ lactose mass flow rate ratio) as well as optimising the process for the production of either gaseous or liquid value-added chemicals. The carbon converted into gas, liquid and solid products varied as follows: $5-41 \%, 33-97 \%$ and $0-59 \%$, respectively. The gas phase was made up of a mixture of $\mathrm{H}_{2}$ (8-58 vol.\%), $\mathrm{CO}_{2}$ (33-85 vol.\%), $\mathrm{CO}(0-15$ vol.\%) and $\mathrm{CH}_{4}$ (0-14 vol.\%). The liquid phase consisted of a mixture of aldehydes: 011\%, carboxylic acids: 0-22\%, monohydric alcohols: 0-23\%, polyhydric-alcohols: 0 48\%, C3-ketones: 4-100\%, C4-ketones: 0-18 \%, cyclic-ketones: 0-15\% and furans: 0$85 \% . \mathrm{H}_{2}$ production is favoured at high pressure, elevated temperature, employing a high amount of catalyst and a concentrated lactose solution. Liquid production is preferential using diluted lactose solutions. At high pressure, the production of C3ketones is preferential using a high temperature and a low amount of catalyst, while a medium temperature and a high amount of catalyst favours the production of furans. The production of alcohols is preferential using medium temperature and pressure and a low amount of catalyst. 
33 Keywords: cheese whey, lactose, aqueous phase reforming, renewable hydrogen and 34 value-added liquids.

35

36

37

38

39

40

41

42

43

44

45

46

47

48

49 


\section{Introduction}

51 Cheese whey is a yellowish liquid resulting from the coprecipitation and removal of

52 milk casein in cheese making processes. On average, during the production of $1 \mathrm{~kg}$ of 53 cheese, $9 \mathrm{~kg}$ of cheese whey is produced as a by-product. This corresponds to 5 million 54 tons a year of whey worldwide [1-4]. The typical composition of this waste is as 55 follows: $4.5-6$ wt.\% lactose, 0.6-1.1 wt.\% proteins, 0.8-1 wt.\% minerals, 0.05-0.9 wt.\% 56 lactic acid, 0.06-0.5 wt.\% fats and 93-94 wt.\% water [1-4]. It has biochemical oxygen 57 demand (BOD) and chemical oxygen demand (COD) values ranging from $27-60 \mathrm{~kg} / \mathrm{m}^{3}$ and $50-102 \mathrm{~kg} / \mathrm{m}^{3}$, respectively. Therefore, it should not be directly discharged into the environment without appropriate treatment and/or valorisation [3] hence cheese whey management has become an important issue [1-4].

Two alternative methods of cheese whey management have traditionally been addressed

63 [3]. The first is the application of physicochemical treatments and filtration 64 technologies. Physicochemical treatments include thermal and isoelectric precipitation $[5,6]$, as well as protein precipitation with coagulant/flocculant agents [7]. Filtration technologies include the use of ultrafiltration membranes and reverse osmosis [2]. The second option relies on the application of biological treatments without valorisation, such as aerobic digestion, and with valorisation such as anaerobic digestion, lactose hydrolysis and fermentation [3]. Aerobic digestion consists of the degradation of the organic matter in the whey at room temperature using short hydraulic retention times

71 [8]. Anaerobic digestion is conducted to convert lactose into propionic acid, ethanol and

72 lactose acetates [9]. Lactose hydrolysis is a preliminary step for other processes [4].

73 Cheese whey fermentation includes the production of ethanol, lactic acid, and hydrogen 
74 and many more [10]. The bioconversion of lactose to ethanol has a theoretical 75 maximum yield of $0.538 \mathrm{~kg}$ ethanol $/ \mathrm{kg}$ of lactose $[11,12]$. Anaerobic fermentation has 76 a theoretical yield of $4 \mathrm{~mol} \mathrm{H}_{2} /$ mol lactose and produces a gas made up of a mixture of $77 \mathrm{H}_{2}, \mathrm{CO}_{2}$ and $\mathrm{CH}_{4}$.

Another interesting and very promising option for the treatment and valorisation of cheese whey effluents is aqueous phase reforming (APR). APR is a catalytic process carried out at quite low temperatures and moderate pressures that allows the simultaneous production of different gases and liquids from an organic feedstock. The gas phase consists of a gas with a high $\mathrm{H}_{2}$ content, the liquid phase being a complex mixture of different organic compounds in water such as alcohols, ketones, acids, esters, aldehydes, furans, phenols and anhydro-sugars [13-16]. The product distribution strongly depends on the operating conditions under which the process is conducted. Therefore, APR can be customised either for the production of gases, helping to reduce the BOD and COD values of the feed or for the production of valuable liquids. In addition, the APR process dispenses with the need to vaporise the water and the organic compounds of the feedstock, thus reducing the energy requirements [17]. To the best of

91 the authors' knowledge, there are no studies in the literature concerning the effect of the 92 operating conditions on the aqueous phase reforming of lactose or cheese whey. 93 Skoglund and Holles [18] developed different pseudomorphic overlayer catalysts $\left(\mathrm{Ni} / \mathrm{Al}_{2} \mathrm{O}_{3}, \mathrm{Co} / \mathrm{Al}_{2} \mathrm{O}_{3}, \mathrm{Pt} / \mathrm{Al}_{2} \mathrm{O}_{3}, \mathrm{Ni} / \mathrm{SiO}_{2}-\mathrm{Al}_{2} \mathrm{O}_{3}, \mathrm{Co} / \mathrm{SiO}_{2}-\mathrm{Al}_{2} \mathrm{O}_{3}\right.$ and $\mathrm{Pt} / \mathrm{SiO}_{2}-\mathrm{Al}_{2} \mathrm{O}_{3}$ ) for the aqueous phase reforming of lactose. Furthermore, works dealing with the aqueous

96 phase reforming of sugars are very scarce. Such studies that there are analyse the 97 aqueous phase reforming of xylitol, sorbitol and galactitol. 
Jiang et al. [19] studied the APR of xylitol for pentane production over Pt/HZSM-5 and

$\mathrm{Ni} / \mathrm{HZSM}-5$, analysing the effects of the reaction temperature, pressure and metal loading on the xylitol conversion and pentane selectivity. Kirilin et al. [20] reported the APR of xylitol in a continuous fixed bed reactor over three catalysts: $\mathrm{Pt} / \mathrm{Al}_{2} \mathrm{O}_{3}, \mathrm{Pt} / \mathrm{TiO}_{2}$ and $\mathrm{Pt}-\mathrm{Re} / \mathrm{TiO}_{2}$. Xi et al. [21] prepared different $\mathrm{M} / \mathrm{NbOPO}_{4}$ multifunctional catalysts

$104(\mathrm{M}=\mathrm{Pt}, \mathrm{Pd}, \mathrm{Ru}, \mathrm{Ir}, \mathrm{Rh}$ and $\mathrm{Ni})$ for alkane production by the hydrodeoxygenation of sorbitol in aqueous solution. Aiouache et al. [22] developed a lumped kinetic model for 106 the aqueous phase reforming of sorbitol. The model was tested at temperatures ranging 107 from $473 \mathrm{~K}$ to $523 \mathrm{~K}$, using monometallic Ni and bimetallic Ni-Pd catalysts supported on $\mathrm{Al}_{2} \mathrm{O}_{3}, \mathrm{ZrO}_{2}$ and $\mathrm{CeO}_{2}$. Kirilin et al. [23] investigated the APR of xylitol and sorbitol using a Pt/ $\mathrm{Al}_{2} \mathrm{O}_{3}$ catalyst. Godina et al. [24] analysed the APR of sorbitol and galactitol using a $\mathrm{Pt} / \mathrm{Al}_{2} \mathrm{O}_{3}$ catalyst in a continuous fixed-bed reactor at $225^{\circ} \mathrm{C}$.

112 Given this background, prior to deal with cheese whey, this work analyses the aqueous 113 phase reforming of a lactose solution, the major organic constituent of this waste, as a 114 possible option for the treatment and valorisation of cheese whey effluents and/or 115 lactose solutions recovered from whey. Specifically, the work addresses the effect of the temperature, pressure, lactose concentration and $\mathrm{W} / \mathrm{m}_{\text {lactose }}$ ratio on the APR of lactose

117 using a Ni-based catalyst. The effect of the operating conditions on the production and 118 selectivity to the different gas and liquid products has never been reported to date.

119 Therefore, the effect of the operating variables on gas, liquid and solid production and 120 on the compositions of the gas and liquid phases has been exhaustively analysed.

121 Furthermore, optimal values for the production of gas and liquid products have also 122 been sought for their selective production. Consequently, this work represents a 
123 challenging and novel investigation not only for the management and valorisation of

124 cheese whey but also for the valorisation of sugars or sugar-based streams.

125

126

\section{Experimental}

\subsection{Materials}

128 The experiments were carried out in a small bench scale continuous unit for 3 hours

129 employing a Ni-La/ $\mathrm{Al}_{2} \mathrm{O}_{3}$ catalyst. The catalyst was prepared by coprecipitation, having

$13028 \%$ (relative atomic percentage) of $\mathrm{Ni}$ expressed as $\mathrm{Ni} /(\mathrm{Ni}+\mathrm{Al}+\mathrm{La})$, an atomic $\mathrm{La} / \mathrm{Al}$

131 ratio of 0.035 and a Brunauer-Emmett-Teller (BET) surface area of $187 \mathrm{~m}^{2} / \mathrm{g}$. The

132 lactose solutions were prepared dissolving D-lactose monohydrate $\left(\mathrm{C}_{12} \mathrm{H}_{22} \mathrm{O}_{11} \cdot \mathrm{H}_{2} \mathrm{O}\right.$

133 Sigma Aldrich, CAS Number 64044-51-5, Bio-Ultra $>99.5 \%$ HPLC) in Milli-Q water.

\section{$135 \quad 2.2$ Experimental rig}

136 The experimental rig used in the experiments was a microactivity unit designed and

137 built by PID (Process Integral Development Eng \& Tech, Spain). It consists of a

138 stainless steel tubular reactor with an inner diameter of $9 \mathrm{~mm}$, heated up by means of an

139 electric furnace $[25,26]$. The system pressure is reached with the aid of a micrometric

140 valve that automatically adapts its position with the help of a rotor. A pressure gauge

141 located at the exit of the reactor measures the pressure of the reaction section. A PDI

142 control system is used to keep the reactor pressure constant during the experiments. The

143 aqueous solutions of lactose are fed into the reactor by means of a high performance

144 liquid chromatography (HPLC) pump (Gilson, model 307). The reaction products (gas

145 and liquids) leave the reactor from its upper part, pass through the valve, where they are

146 depressurised, and arrive at the condensation system. This system consists of several 
147 condensers where the liquid products are separated from the gas mixture at intervals of

$1481 \mathrm{~h}$ to analyse the evolution over time of the liquid phase. The gas mixture is made up of

$149 \mathrm{~N}_{2}$, used as an internal standard, and the different gaseous products formed during the

150 aqueous phase reforming reaction. An Agilent M3000 micro chromatograph equipped

151 with thermal conductivity detectors (TCD) was used for the online analysis of the gas

152 phase. The liquid fractions were collected and analysed offline with a gas

153 chromatograph (Agilent 7890 GC-system, model G3440A) equipped with Flame

154 Ionization (FID) and Mass Spectrometry (MS) detectors. A schematic diagram of the

155 experimental system is shown in Figure S1.

156

157

$158 \quad 2.3$ Operating conditions, response variables and statistical analyses

159 The effect of the temperature $\left(200-240{ }^{\circ} \mathrm{C}\right)$, pressure $(38-50$ bar $)$, lactose concentration

160 (1-10 wt.\%) and catalyst mass/lactose mass flow rate ratio $\left(\mathrm{W} / \mathrm{m}_{\text {lactose }}=10-40 \mathrm{~g}\right.$ catalyst

$161 \mathrm{~min} / \mathrm{g}$ lactose) was experimentally analysed using a design of experiments (DOE) with

162 statistical analysis of the results carried out by means of an analysis of variance

163 (ANOVA). The effect of the operating conditions on the process was analysed for the

164 following response variables: global lactose conversion (X lactose, \%), carbon

165 conversion to gas, liquid and solid products (CC gas \%, CC liq \%, and $\mathrm{CC}$ sol \%) as well as the composition of the gas $\left(\mathrm{N}_{2}\right.$ and $\mathrm{H}_{2} \mathrm{O}$ free, vol.\%) and liquid (relative

167 chromatographic area free of water and un-reacted lactose, \%). Table S1 summarises

168 the response variables and the analytical methods used for their calculation.

172 The experiments, listed in Table S2, were designed using a $2^{\mathrm{k}}$ factorial design, where $\mathrm{k}$

173 indicates the number of factors studied ( 4 operating conditions) and $2^{\mathrm{k}}$ represents the 
174 number of runs (16). In addition, 5 replicates at the centre of the variation interval of

175 each factor were carried out in order to evaluate both the experimental error and the 176 curvature shown by the evolution of each variable. This factorial design minimises the

177 number of experiments needed to understand the effect on the process of the operating

178 variables and the interactions between them. As the response variables did not show a

179 linear trend, this design was increased with 8 axial runs following a Box-Wilson Central

180 Composite Face Centred (CCF, $\alpha: \pm 1)$ design, enabling the operating variables and

181 interactions responsible for the curvature to be identified without modifying the range

182 of study initially considered for the operating variables. The lower and upper limits of

183 all the operating variables were normalised from -1 to 1 (codec factors) to identify their 184 influence in comparable terms.

185

186 For the analysis of the results, firstly the evolution over time of the response variables 187 was studied. To do this, the results were divided into three intervals, each corresponding 188 to the average value of the studied response variables obtained during each one of the 189 three hours of experiment. All these values (three per experiment) have been compared 190 using a one-way analysis of variance (one-way ANOVA) and Fisher's least significant 191 difference (LSD) test, both with 95\% confidence. The results of the ANOVA analyses 192 are provided as p-values. P-values lower than 0.05 indicate that at least two values are 193 significantly different. Furthermore, the LSD test was used to compare pairs of data, i.e. 194 either between two intervals of the same experiment or between two intervals of two 195 different experiments. The results of the LSD tests are presented graphically in the form of LSD bars. To ensure significant differences between any pairs of data, their LSD bars

197 must not overlap. Secondly, the effect of the operating conditions was studied 198 considering the results corresponding to the first hour using a statistical analysis of 
variance (one-way ANOVA) test with 95\% confidence. This strategy allows not having

200 to include the effect of the variations with time of the different response variables in the analysis. In addition, the cause-effect Pareto principle was used to calculate the relative importance of the operating variables on each response variable.

\subsection{Possible reaction network for lactose aqueous phase reforming}

205 A plausible reaction pathway for the aqueous phase reforming of lactose is shown in 206 Figure 1. The reaction network includes the formation of gases and liquid products. The 207 formation of these compounds starts with an initial lactose decomposition by hydrolysis 208 into glucose and galactose [27], which can subsequently be decomposed into other 209 intermediate liquids. Three possible parallel routes explain the formation of 210 intermediate liquids from these monomers: glucose/galactose isomerisation to fructose 211 (A) [27-30] and/or retro-aldol fragmentation to erythrose and 2-hydroxyacetaldehyde (B) [30] and/or dehydration to 5-hydroxymethyl-2-furancarboxaldehyde [21, 22, 27, 28,

213 31-33] (C). Gases, mainly $\mathrm{H}_{2}$ and $\mathrm{CO}$, are produced by the thermal decomposition

214 and/or reforming reactions of the lactose and all the liquid intermediates (Eq.1) as well 215 as by all the decarbonylation reactions that release CO. In addition, the WGS reaction 216 (Eq.2) and the methanation reaction (the inverse of methane steam reforming reactions) 217 (Eq.3-4) are also possible, explaining the presence of $\mathrm{CO}_{2}$ and $\mathrm{CH}_{4}$ in the gas phase [34, $21835]$.

$220 \mathrm{CO}+\mathrm{H}_{2} \mathrm{O} \Leftrightarrow \mathrm{CO}_{2}+\mathrm{H}_{2}$

$221 \mathrm{CO}+3 \mathrm{H}_{2} \Leftrightarrow \mathrm{CH}_{4}+\mathrm{H}_{2} \mathrm{O}$

$222 \mathrm{CO}_{2}+4 \mathrm{H}_{2} \Leftrightarrow \mathrm{CH}_{4}+2 \mathrm{H}_{2} \mathrm{O}$ 
224 2.4.1 Formation of products via fructose: route A

225 2,3-dihydroxypropanal and/or 1,3-dihydroxypropan-2-one are produced from fructose

226 via retro-aldol fragmentation [27-30]. The latter can undergo hydrogenation to produce

227 glycerol and/or decarbonylation to form ethane-1,2-diol [29, 30]. On the one hand,

228 glycerol can be dehydrated to 1-hydroxypropan-2-one, which can then undergo

229 hydrogenation to produce propane-1,2-diol [13, 14, 36-38]. Propane-1,2-diol can

230 subsequently be dehydrated to form propan-2-one and/or propionaldehyde, which can

231 be hydrogenated to propan-2-ol and propan-1-ol, respectively [36]. Afterwards, these

232 two chemicals can be further transformed into butane and propane [14, 36-38]. Ethanol

233 might be formed from the hydrogenation of propan-2-ol [14]. On the other hand,

234 ethane-1,2-diol can evolve towards 2-hydroxyacetaldehyde formation via

235 dehydrogenation, which might lead to the formation of methanol by decarbonylation

$236[13,14]$, or to the production of acetaldehyde and/or ethanol via dehydration and

237 dehydration/hydrogenation, respectively [13, 14, 37]. Acetaldehyde can subsequently be

238 transformed into acetic acid and/or methane, while ethene and ethane can be produced

239 from ethanol $[13,14,37]$. 


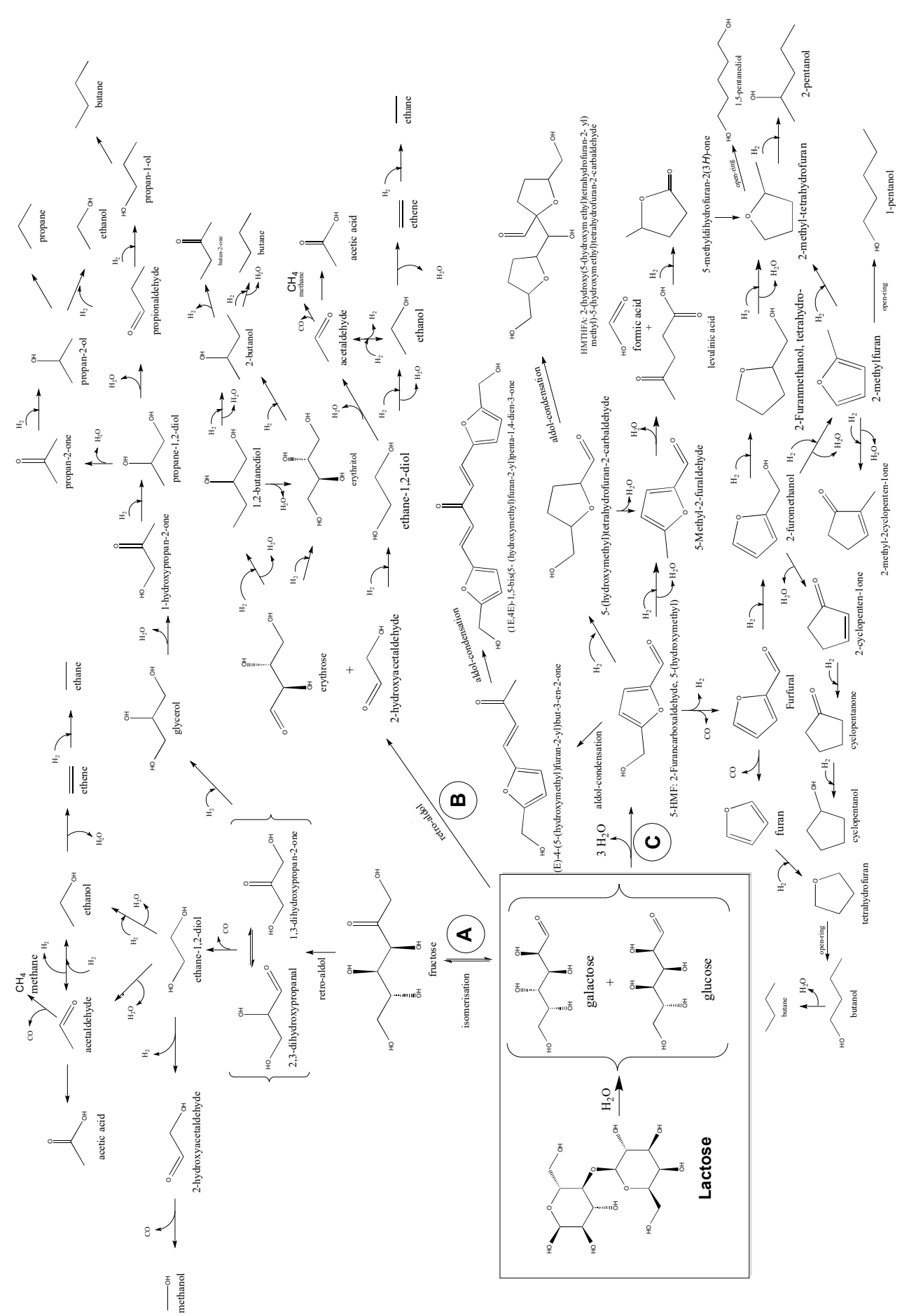

259 Figure 1. Possible reaction pathways during the aqueous phase reforming of lactose.

2.4.2 Formation of products via erythrose and 2-hydroxyacetaldehyde: route B

262 Erythrose can undergo further hydrogenation to erythritol and/or 
263 hydrogenation/dehydration to 1,2-butane-diol. Subsequently, 2-butanol can be produced 264 via hydrogenation/dehydration [30]. Butan-2-one and butane can be produced from the 265 dehydrogenation and hydrogenation/dehydration of this latter compound. Ethane-1,2266 diol can be produced from the hydrogenation of 2-hydroxyacetaledhyde and can either 267 undergo further hydrogenation/dehydration to ethanol and/or dehydration to 268 acetaldehyde. Ethanol can subsequently be dehydrated to ethene and hydrogenated to 269 produce ethane, while acetaldehyde can subsequently be transformed into acetic acid 270 and/or methane $[13,14,37]$.

273 5-hydroxymetyl-2-furancarboxaldehyde can be transformed into 5-methyl-2-

274 furaldehyde via hydrogenation/dehydration, and/or hydrogenated to 5-hydroxymethyl-

275 tetrahydrofuran-2-carbaldehyde and/or decarbonylated/dehydrogenated to produce

276 furfural and/or can evolve to (E)-4-(5-(hydroxymethyl)furan-2-yl)but-3-en-2-one via

277 aldol-condensation [28, 31, 39, 40]. Subsequently, 5-methyl-2-furaldehyde can be 278 dehydrated giving formic acid and levulinic acid. This latter can be hydrogenated to 5279 methyldihydrofuran-2(3H)-one [33, 39, 40]. In addition, (1E,4E)-1,5-bis(5280 (hydroxymethyl)furan-2-yl)penta-1,4-dien-3-one and 2-(hydroxy(5-

281 (hydroxymethyl)tetrahydrofuran-2- yl)methyl)-5(hydroxymethyl)tetrahydrofuran-2282 carbaldehyde can be produced from (E)-4-(5-(hydroxymethyl)furan-2-yl)but-3-en-2-one 283 and 5-hydroxymethyl-tetrahydrofuran-2-carbaldehyde, respectively, via retro-aldol condensation $[28,31,39,40]$. Furthermore, furfural can undergo hydrogenation to 2285 furomethanol and/or decarbonylation to furan [32, 39, 41]. Furan can be hydrogenated 286 to tetrahydrofuran, which can firstly evolve to butanol through ring opening and 
subsequently to butane via dehydration [42]. 2-furomethanol can undergo further

hydrogenation to 2- furanmethanol, tetrahydro- and/or hydrogenation/dehydration to 2methylfuran and/or dehydration to 2-cylcopenten-1one [39]. Subsequently, 2-

furanmethanol, tetrahydro can be hydrogenated/dehydrated to 2-methyl-tetrahydrofuran.

291 2-pentanol and 1,5-pentane-diol can be obtained from this latter chemical through

292 hydrogenation and ring opening, respectively [32]. 2-methylfuran can be hydrogenated

293 to 2-methyl-tetrahydrofuran and/or hydrogentated/dehydrated to 2methyl-2cyclopenten-

294 1one and/or evolve to 1-pentanol via ring opening. Cyclopentanone can be produced

295 from the hydrogenation of 2cyclopenten-1one. This latter can be hydrogenated to

296 cyclopentanol [32].

297

\section{Results and discussion}

3.1 Global lactose conversion and carbon distribution: CC gas, CC liq and CC sol.

300 A complete and steady global lactose conversion (X lactose) was achieved in all the experiments, indicating that all the lactose was converted into gas, liquid and solid products. The $\mathrm{C} / \mathrm{O}$ ratio close to 1 of lactose allows a complete conversion to be achieved [34, 43]. Figure S2 shows the CC gas, CC liq and CC sol obtained for the experiments, which vary as follows: $5-41 \%, 33-97 \%$ and $0-59 \%$, respectively. Increases and reductions in these variables over time are detected in some experiments.

The general trend for the $\mathrm{CC}$ gas is a steady evolution. However, decreases over time occur for some experiments $(2-4,6,8,13-15,23,24,27$ and 29). These decreases are particularly marked for experiments $8,13,15$ and 29 . One exception is experiment 8 , where a lower $\mathrm{W} / \mathrm{m}_{\text {lactose }}$ ratio ( $10 \mathrm{~g}$ catalyst $\mathrm{min} / \mathrm{g}$ lactose) was used. The drops for the 
311 CC gas are more marked at operating conditions under which gas production is more 312 favoured [25]. The CC liq displays increases (experiments 1,9-13, 23-25, 27-29) and 313 decreases (experiments 6 and 8) over time. In particular, sharp increases are observed 314 for runs 1, 11 and 13. Most of the slight decreases observed for the CC gas take place 315 along with increases in the CC liq (experiments 13, 14, 23, 24, 27 and 29). This 316 evolution of the $\mathrm{C}$ product distribution is consistent with the work of Wawrzetz et al. 317 [37] and Remón et al. [25], who demonstrated that the formation of $\mathrm{H}_{2}$ and $\mathrm{CO}_{2}$ via 318 dehydrogenation followed by decarbonylation with the subsequent water gas shift is one 319 of the fastest reactions during aqueous phase reforming. In addition, gas production 320 decreases with catalyst deactivation, thus increasing the production of intermediate 321 liquid products.

322 Sharp increases in the $\mathrm{CC}$ sol are observed for experiments 6,8 and 15 , while decreases 323 take place for experiments 1 and 11. Most of the decreases in the CC sol occur along 324 with increases in the CC liq and vice versa (6 and 8-10). The decrease observed in the $325 \mathrm{CC}$ gas for experiments 13 and 15 accounts for the increases in the CC liq and CC sol, 326 respectively, which might indicate a change in the product selectivity over time.

327 Experiments 6 and 8 were performed using the highest temperature $\left(240{ }^{\circ} \mathrm{C}\right)$ and lactose 328 concentration (10 wt.\%), along with the lowest $\mathrm{W} / \mathrm{m}_{\text {lactose }}$ ratio used in this work. Sugar 329 molecules are unstable at the temperatures of this process and quickly decompose 330 through pyrolysis, leading to the formation of char particles and gases [35]. This solid 331 residue (char) can also be obtained from polymerised degradation products such as 332 humic acids and large organic compounds ranging from $\mathrm{C}_{8}$ to $\mathrm{C}_{15}[23,27,28,31,33$, $33339,41]$. The formation of these macromolecules can occur from furfural and 5334 hydroxymethyl-2-furancarboxaldehyde (route C). Furthermore, both lactose monomers 335 (glucose and galactose) can react with other liquid intermediates or with 5- 
336 hydroxymethyl-2-furancarboxaldehyde by cross-polymerisation. These reactions are

337 favoured at high temperature and pressure [27, 28, 31, 33]. In addition, char obtained

338 from the pyrolysis of different biomass materials has been reported to have catalytic

339 activity for the reforming and cracking of different hydrocarbons [44-50], which

340 accounts for the decreases over time in the CC sol $[34,35]$ and the increases in the CC

341 liq observed in some experiments.

343 The specific effect of the operating conditions as well as their possible interactions on

344 the process has been studied considering the results obtained during the first hour of

345 reaction. The models created in terms of codec factors considering the ANOVA analysis

346 and the relative importance of the operating variable taking into account the cause-

347 effect Pareto analysis are shown in Table S3. The CC gas is strongly affected by the

348 lactose concentration, both linear and quadratic terms, and the interaction between the

349 temperature and the $\mathrm{W} / \mathrm{m}_{\text {lactose }}$ ratio $\left(\mathrm{T}^{2} \mathrm{~W}\right)$. An increase in the lactose concentration

350 increases the CC gas. The temperature and its interaction with the $\mathrm{W} / \mathrm{m}_{\text {lactose }}\left(\mathrm{T}^{2} \mathrm{~W}\right)$ are

351 the operating variables with the greatest effect on the $\mathrm{CC}$ liq and the $\mathrm{CC}$ sol. In addition,

352 significant interactions between the operating variables also influence the $\mathrm{CC}$ gas, CC

353 liq and CC sol.

355 Figure 2 illustrates the effect of the operating variables and the most important 356 interactions on the product distribution in carbon basis, according to the ANOVA 357 analysis. Specifically, Figures $2 \mathrm{a}$ and $\mathrm{b}$, e and $\mathrm{f}$, and $\mathrm{i}$ and $\mathrm{j}$ show the effects on the CC 358 gas, $\mathrm{CC}$ liq and $\mathrm{CC}$ sol of the reaction temperature, employing a pressure of 38 bar for $359 \mathrm{~W} / \mathrm{m}_{\text {lactose }}$ ratios of 10 and $40 \mathrm{~g}$ catalyst min/g lactose, when feeding 1 and $10 \mathrm{wt} . \%$ 
360 lactose solutions, respectively. Figures $2 \mathrm{c}$ and $\mathrm{d}, \mathrm{g}$ and $\mathrm{h}$, and $\mathrm{k}$ and 1 display the effect 361 of the temperature for $\mathrm{W} / \mathrm{m}_{\text {lactose }}$ ratios of 10 and $40 \mathrm{~g}$ catalyst $\mathrm{min} / \mathrm{g}$ lactose employing
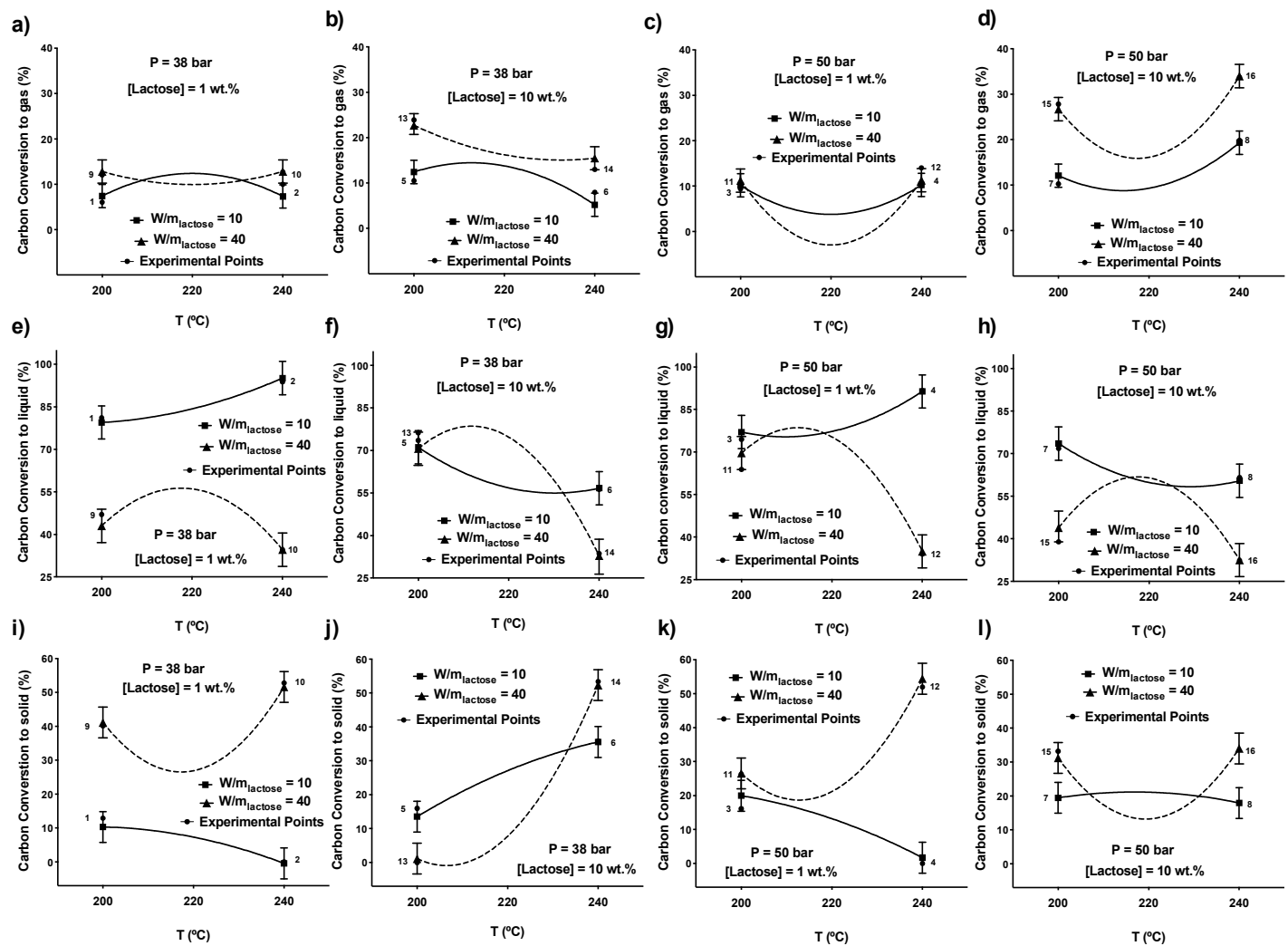

Figure 2. Interaction plots for the initial CC gas (a-d), CC liq (e-h) and CC sol conversion (i-l). Bars are LSD intervals with $95 \%$ confidence.

\subsubsection{Carbon conversion to gas: CC gas}

370 The effect of the temperature on the CC gas depends on the pressure and concentration

371 of lactose in the solution. At 38 bar, two trends are observed depending on the lactose

372 concentration. When a 1 wt.\% lactose solution is fed, the CC gas is low (8-14\%) and

373 neither the temperature nor the $\mathrm{W} / \mathrm{m}_{\text {lactose }}$ exert a significant effect on the $\mathrm{CC}$ gas.

374 Conversely, for a $10 \mathrm{wt} . \%$ lactose solution, the temperature has a greater influence on

375 the $\mathrm{CC}$ gas and the effect of the temperature depends on the $\mathrm{W} / \mathrm{m}_{\text {lactose }}$ ratio. For $10 \mathrm{~g}$ 
376 catalyst $\mathrm{min} / \mathrm{g}$ lactose, the $\mathrm{CC}$ gas remains low and steady (around 12\%) between 200

377 and $220^{\circ} \mathrm{C}$ and decreases slightly with a further increase in the temperature up to 240

$378{ }^{\circ} \mathrm{C}$. For a $\mathrm{W} / \mathrm{m}_{\text {lactose }}$ ratio of $40 \mathrm{~g}$ catalyst $\mathrm{min} / \mathrm{g}$ lactose an increase in the temperature

379 from 200 to $240{ }^{\circ} \mathrm{C}$ decreases the $\mathrm{CC}$ gas. In general, the $\mathrm{CC}$ gas is relatively low,

380 which indicates that gas formation is not favoured at low pressure $[19,23,51]$. In

381 addition, at 38 bar feeding a $10 \mathrm{wt} . \%$ lactose solution, the $\mathrm{W} / \mathrm{m}_{\text {lactose }}$ ratio significantly

382 promotes gas production and an increase from 10 to $40 \mathrm{~g}$ catalyst $\mathrm{min} / \mathrm{g}$ lactose

383 produces an increase in the $\mathrm{CC}$ gas due to its positive kinetic effect on cracking and

384 reforming reactions [25].

At 50 bar of pressure, the temperature exerts a greater effect on gas production than at

38738 bar, and greater amounts of CC gas are obtained, especially for concentrated lactose

388 solutions and high $\mathrm{W} / \mathrm{m}_{\text {lactose }}$ ratios. These conditions favour gas production from

389 lactose and its liquid intermediate due to the positive kinetic effect of the catalyst. An

390 increase in pressure favours gas formation [25] due to a increase in the rate of C-C bond

391 cleavage reactions [52]. An increase in the CC gas when increasing the total pressure of

392 the system has also been reported for the APR of xylitol [19] and other oxygenated

393 compounds $[17,53,54]$.

Regardless of the lactose concentration, the gas production displays a minimum with to $220^{\circ} \mathrm{C}$ decreases the $\mathrm{CC}$ gas, while a further increase from 220 to 240 increases the

$398 \mathrm{CC}$ gas regardless of the lactose concentration and $\mathrm{W} / \mathrm{m}_{\text {lactose }}$ ratio. This evolution

399 depends on the $\mathrm{W} / \mathrm{m}_{\text {lactose }}$ ratio. For $10 \mathrm{~g}$ catalyst $\mathrm{min} / \mathrm{g}$ lactose the $\mathrm{CC}$ gas is relatively

400 low and the decrease and the subsequent increase in the $\mathrm{CC}$ gas observed with the 
401 variation in temperature are not as marked as for $40 \mathrm{~g}$ catalyst $\mathrm{min} / \mathrm{g}$ lactose. For $40 \mathrm{~g}$

402 catalyst $\mathrm{min} / \mathrm{g}$ lactose a pronounced decay followed by a sharp increase in the CC gas

403 occurs. At low temperatures $\left(200-220^{\circ} \mathrm{C}\right)$ the positive kinetic effect helps to shift the

404 reaction towards the formation of intermediate liquids, increasing the $\mathrm{CC}$ liq.

405 Conversely, a further increase in temperature up to $240{ }^{\circ} \mathrm{C}$ favours the transformation of 406 these liquid products into gases, decreasing the CC liq [25]. As regards the $\mathrm{W} / \mathrm{m}_{\text {lactose }}$ 407 ratio, an increase from 10 to $40 \mathrm{~g}$ catalyst $\mathrm{min} / \mathrm{g}$ lactose does not greatly modify the CC 408 gas for a $1 \mathrm{wt} . \%$ lactose solution, while it increases the CC gas for a $10 \mathrm{wt} . \%$ lactose 409 solution within the whole temperature range considered. Gas production is kinetically 410 favoured at high pressure and using a concentrated lactose solution due to the positive 411 kinetic effect of these variables [25].

413 The effect of the lactose concentration can be gathered comparing Figures $2 \mathrm{a}$ with $\mathrm{b}$ 414 and $2 \mathrm{c}$ with $\mathrm{d}$. This effect depends on the pressure and $\mathrm{W} / \mathrm{m}_{\text {lactose }}$ ratio. For $10 \mathrm{~g}$ catalyst $415 \mathrm{~min} / \mathrm{g}$ lactose, the effect of the lactose concentration is very weak regardless of the 416 pressure. Conversely, for $40 \mathrm{~g}$ catalyst $\mathrm{min} / \mathrm{g}$ lactose the lactose concentration exerts a 417 greater influence. At 38 bar, the $\mathrm{CC}$ gas increases within the whole temperature range 418 considered, especially between 200 and $220^{\circ} \mathrm{C}$. At 50 bar, a great increase in the $\mathrm{CC}$ 419 gas takes place for $40 \mathrm{~g}$ catalyst $\mathrm{min} / \mathrm{g}$ lactose regardless of the reaction temperature.

421 As regards the effect of the pressure, a comparison between Figures 2 a with $2 \mathrm{c}$ and $2 \mathrm{~b}$ 422 with $\mathrm{d}$ shows the effect of this operating variable on the CC gas when 1 and $10 \mathrm{wt} . \%$ 423 lactose solution are used, respectively. For a $1 \mathrm{wt} . \%$ lactose solution, the effect of the 424 pressure is very weak. Conversely, for $40 \mathrm{~g}$ catalyst $\mathrm{min} / \mathrm{g}$ lactose the decrease observed 425 in the CC gas is slightly greater. For a $10 \mathrm{wt} . \%$ lactose solution the CC gas does not 
426 greatly vary when the pressure increases from 38 to 50 bar between 200 and $220{ }^{\circ} \mathrm{C}$,

427 while a great increase in the $\mathrm{CC}$ gas takes places between 220 and $240{ }^{\circ} \mathrm{C}$. The effect of 428 pressure is only significant when gas production is favoured [25]. The pressure exerts a

429 significant influence on the kinetics of the process, since an increase in the total

430 pressure of the system also increases the partial pressures of lactose and its

431 intermediates, increasing the reaction rates of lactose APR reactions and thus enhancing 432 gas production as reported in other works studying the APR of glycerol $[17,53,54]$ and 433 sorbitol [19, 21].

\subsubsection{Carbon conversion to liquid and solid products: CC liq and CC sol}

The CC liq and CC sol show opposite tendencies, i.e. an increase in the former takes

437 place along with a decrease in the latter and vice versa. A statistically significant and 438 high relationship ( $\mathrm{p}$-value $<0.0001 ; \mathrm{R}^{2}=0.91$ ) was found between the $\mathrm{CC}$ liq and $\mathrm{CC}$ 439 sol by means of the Spearman's multivariate test.

441 The effect of the temperature on the CC liq and CC sol depends on the concentration of

442 lactose in the solution and the $\mathrm{W} / \mathrm{m}_{\text {lactose }}$ ratio. For a $1 \mathrm{wt} . \%$ lactose solution and a

$443 \mathrm{~W} / \mathrm{m}_{\text {lactose }}$ ratio of $10 \mathrm{~g}$ catalyst $\mathrm{min} / \mathrm{g}$ lactose, an increase in the reaction temperature 444 increases the $\mathrm{CC}$ liq and decreases the $\mathrm{CC}$ sol regardless of the pressure. Conversely, 445 when a $\mathrm{W} / \mathrm{m}_{\text {lactose }}$ ratio of $40 \mathrm{~g}$ catalyst $\mathrm{min} / \mathrm{g}$ lactose is used, the $\mathrm{CC}$ liq increases 446 between $200^{\circ}$ and $220^{\circ}$ and decreases with a further increase in the temperature up to $447240{ }^{\circ} \mathrm{C}$ regardless of the lactose concentration. For a $10 \mathrm{wt} . \%$ lactose solution different 448 evolutions for the $\mathrm{CC}$ liq and $\mathrm{CC}$ sol are observed depending on the temperature, 449 pressure and $\mathrm{W} / \mathrm{m}_{\text {lactose }}$ ratio. An increase in temperature decreases the CC liq and 450 increases the $\mathrm{CC}$ sol when a $\mathrm{W} / \mathrm{m}_{\text {lactose }}$ ratio of $10 \mathrm{~g}$ catalyst $\mathrm{min} / \mathrm{g}$ lactose is used. The 
451 increase in the $\mathrm{CC}$ sol only occurs at low pressure (38 bar), while at high pressure (50

452 bar) the $\mathrm{CC}$ sol remains steady with the temperature and the decrease in the $\mathrm{CC}$ liq

453 occurs along with an increase in the $\mathrm{CC}$ gas. Conversely, for $40 \mathrm{~g}$ catalyst $\mathrm{min} / \mathrm{g}$ lactose

454 the CC liq increases between 200 and $220{ }^{\circ} \mathrm{C}$ and decreases with a further increase in

455 temperature up to $240{ }^{\circ} \mathrm{C}$.

456

457 The effect of the pressure on the $\mathrm{CC}$ liq/CC sol can be gathered comparing Figures $2 \mathrm{e} / \mathrm{i}$

458 with $\mathrm{g} / \mathrm{k}$ and $2 \mathrm{f} / \mathrm{j}$ with $\mathrm{h} / \mathrm{l}$ for lactose concentrations of 1 and $10 \mathrm{wt} . \%$, respectively.

459 The effect of the pressure is at its highest for $40 \mathrm{~g}$ catalyst $\mathrm{min} / \mathrm{g}$ lactose, and an

460 increase from 38 to 50 bar between 200 and $230{ }^{\circ} \mathrm{C}$ increases the $\mathrm{CC}$ liq and reduces the

461 CC sol for a $1 \mathrm{wt} . \%$ lactose solution. For a $10 \mathrm{wt} . \%$ lactose solution an increase in the

462 pressure from 38 to 50 bar decreases the CC liq and increases the $\mathrm{CC}$ sol between 200

463 and $220^{\circ} \mathrm{C}$, while minor changes occur between 220 and $240{ }^{\circ} \mathrm{C}$.

464

465 The effect of the $\mathrm{W} / \mathrm{m}_{\text {lactose }}$ ratio depends on the lactose concentration and pressure. At

$46638 \mathrm{bar}$, an increase in the $\mathrm{W} / \mathrm{m}_{\text {lactose }}$ ratio from 10 to $40 \mathrm{~g}$ catalyst $\mathrm{min} / \mathrm{g}$ lactose

467 decreases the CC liq and increases the $\mathrm{CC}$ sol for a $1 \mathrm{wt} \% \%$ lactose solution. For a 10

468 wt.\% lactose solution, an increase in the $\mathrm{W} / \mathrm{m}_{\text {lactose }}$ ratio from 10 to $40 \mathrm{~g}$ catalyst $\mathrm{min} / \mathrm{g}$

469 lactose increases the $\mathrm{CC}$ liq and decreases the $\mathrm{CC}$ sol between 210 and $230{ }^{\circ} \mathrm{C}$. A

470 further increase in temperature up to $240{ }^{\circ} \mathrm{C}$ decreases the $\mathrm{CC}$ liq and increases the $\mathrm{CC}$

471 sol. The analysis of the liquid product reveals that the concentration of furans in the

472 liquid increases when increasing the concentration of lactose in the solution for a low

$473 \mathrm{~W} / \mathrm{m}_{\text {lactose }}$ ratio at 38 bar. This suggests that polymerisation reactions might occur with a

474 lesser spread as the concentration of lactose increases. Therefore, for a diluted lactose

475 solution, an increase in the $\mathrm{W} / \mathrm{m}_{\text {lactose }}$ ratio promotes polymerisation reactions, thus 
476 increasing the CC sol. Conversely, for a concentrated lactose solution the thermal

477 decomposition of lactose might be responsible for char formation and an increase in the

$478 \mathrm{~W} / \mathrm{m}_{\text {lactose }}$ ratio mitigates char formation and/or helps its removal. At temperatures

479 between $230{ }^{\circ} \mathrm{C}$ and $240{ }^{\circ} \mathrm{C}$ this increase in the $\mathrm{W} / \mathrm{m}_{\text {lactose }}$ ratio increases char

480 production, probably due to the higher spread of polymerisation reactions. At 50 bar, an

481 increase from 10 to $40 \mathrm{~g}$ catalyst $\mathrm{min} / \mathrm{g}$ lactose does not significantly influence the CC

482 liq and $\mathrm{CC}$ sol between 200 and $220^{\circ} \mathrm{C}$ for a $1 \mathrm{wt} . \%$ lactose solution. Conversely, for a

$48310 \mathrm{wt} . \%$ lactose solution, this increment in the $\mathrm{W} / \mathrm{m}_{\text {lactose }}$ ratio decreases and increases

484 the $\mathrm{CC}$ liq and $\mathrm{CC}$ sol, respectively, from 200 to $210^{\circ} \mathrm{C}$. Between 220 and $240{ }^{\circ} \mathrm{C}$, an

485 increase in the $\mathrm{W} / \mathrm{m}_{\text {lactose }}$ ratio from 10 to $40 \mathrm{~g}$ catalyst $\mathrm{min} / \mathrm{g}$ lactose decreases the $\mathrm{CC}$

486 liq and increases the CC sol regardless of the pressure due to the greater spread of

487 condensation and cross-polymerisation reactions [27, 28, 31, 33].

489 The temperature exerts a positive kinetic effect on the process. When a low amount of

490 catalyst is used, an increase in the temperature helps to decrease solid formation.

491 However, an increase in the amount of catalyst in the bed also produces a greater spread

492 of polymerisation, cross-polymerisation and condensation reactions from furfural and 5-

493 hydroxymethyl-2-furancarboxaldehyde. These two latter compounds, found in some of

494 the liquid condensates, might lead to the formation of large molecules $[23,27,28,31$,

$49533,39,41]$ that are insoluble in water and can promote char formation [27, 28, 31, 33].

496 These chemical reactions leading to the formation of polymers are favoured at high

497 temperature and pressure. Therefore, at temperatures between 220 and $240{ }^{\circ} \mathrm{C}$ the $\mathrm{CC}$

498 liq decreases and the CC sol increases very sharply as high temperatures promote

499 polymerisation reactions [27, 28, 31, 33] and lactose decomposition through pyrolysis,

500 leading to the formation of char particles [35]. 
5023.2 Effect of the operating conditions on the volumetric composition of the gas

503 Figure S3 shows the composition of the gas obtained for the experiments divided into 504 three intervals of 60 minutes each. The gas phase is made up of a mixture of $\mathrm{H}_{2}(8-58$ vol.\%), $\mathrm{CO}_{2}\left(33-90\right.$ vol.\%), $\mathrm{CO}\left(0-18\right.$ vol.\%) and $\mathrm{CH}_{4}(0-14$ vol.\%). As regards the

506 evolution of the gas composition over time, $\mathrm{H}_{2}$ and $\mathrm{CO}_{2}$ display the greatest variations.

507 Statistically significant decreases are detected for the proportion of $\mathrm{H}_{2}$, while increases 508 occur for the relative amount of $\mathrm{CO}_{2}$ in the gas.

509

510 This $\mathrm{H}_{2}$ depletion was also observed in the work of Kirilin et al. [23] during the APR of 511 xylitol and sorbitol. They reported that the oxygenated compounds formed during the 512 APR process might adsorb on the surface of the catalyst, thus hindering the catalyst 513 performance and leading to a decrease in the $\mathrm{H}_{2}$ selectivity. This development is also 514 responsible for the increase in the proportion of $\mathrm{CO}_{2}$ in the gas over time, as thermal 515 lactose decomposition might be more favoured over reforming with the progressive 516 deactivation of the catalyst. In addition, the decrease in the proportion of $\mathrm{H}_{2}$ in the gas 517 may also be attributed to the structural changes of the alumina of the support [23]. The 518 alumina of the catalyst support can be transformed into boehmite by water $[52,55,56]$.

519 This transformation was reported in a previous work where this catalyst was used for 520 the APR of crude glycerol [25].

522 The proportions of $\mathrm{CO}$ and $\mathrm{CH}_{4}$ remain steady for the vast majority of the experiments.

523 In general, small variations are detected for the proportion of $\mathrm{CO}$ in the gas. One 524 exception is experiment 16 , where a relatively high increase in the proportion of CO 525 over time takes place. The proportion of $\mathrm{CH}_{4}$ shows small variations over time. In some 
526 experiments an initial decrease in the proportion of $\mathrm{CH}_{4}$ takes place between the first

527 and second hour of reaction, along with a posterior increase in its relative amount

528 between the second and third hour. However, these variations are not important from a

529 practical point of view due to the relatively low amount of $\mathrm{CH}_{4}$ in the gas.

530

531 The specific effects of the operating conditions as well as their possible interactions on

532 the volumetric composition of the gas were studied considering the results obtained

533 during the first 60 minutes of reaction. Table S4 shows the results of the statistical

534 analyses performed. These analyses show that the temperature, the $\mathrm{W} / \mathrm{m}_{\text {lactose }}$ ratio and

535 the interaction between these two operating variables are the variables with the greatest

536 influence on the proportion of $\mathrm{H}_{2}$ in the gas. The temperature and the $\mathrm{W} / \mathrm{m}_{\text {lactose }}$ are the

537 operating variables exerting the greatest influence on the proportion of $\mathrm{CO}_{2}$. The

538 concentration of $\mathrm{CO}$ in the gas is mostly affected by the interactions between the

539 temperature and the concentration of lactose $\left(\mathrm{TC}\right.$ and $\left.\mathrm{T}^{2} \mathrm{C}\right)$. The concentration of lactose

540 substantially influences the relative amount of $\mathrm{CH}_{4}$ in the gas.

542 Figure 3 illustrates the effect of these interactions according to the ANOVA analysis on

543 the composition of the gas. The effects of the reaction temperature, at 38 bar and 50 bar

544 for $\mathrm{W} / \mathrm{m}_{\text {lactose }}$ ratios of 10 and $40 \mathrm{~g}$ catalyst $\mathrm{min} / \mathrm{g}$ lactose, feeding a $1 \mathrm{wt} . \%$ lactose

545 solution, are shown in Figures $3 \mathrm{a}$ and $\mathrm{c}$, e and $\mathrm{g}, \mathrm{i}$ and $\mathrm{k}$, and $\mathrm{m}$ and o. Figures $3 \mathrm{~b}$ and

$546 \mathrm{~d}, \mathrm{f}$ and $\mathrm{h}, \mathrm{j}$ and $\mathrm{l}$, and $\mathrm{n}$ and $\mathrm{p}$ display the effect of the temperature and the $\mathrm{W} / \mathrm{m}_{\text {lactose }}$

547 ratio at 38 and 50 bar for a $10 \mathrm{wt} . \%$ lactose solution. 
549 The reaction temperature exerts a great influence on the concentrations of $\mathrm{H}_{2}$ and $\mathrm{CO}_{2}$.

550 An increase in the former gas occurs along with a decrease in the latter and vice versa, 551 as explained above. Therefore, the effect of the operating conditions is fully described

552 for the proportion of $\mathrm{H}_{2}$, the relative amount of $\mathrm{CO}_{2}$ showing the opposite effect in most 553 cases. In general, two trends are observed for the evolution of $\mathrm{H}_{2}$ and $\mathrm{CO}_{2}$ depending on 554 the $\mathrm{W} / \mathrm{m}_{\text {lactose }}$ ratio. For a low $\mathrm{W} / \mathrm{m}_{\text {lactose }}$ ratio ( $10 \mathrm{~g}$ catalyst $\mathrm{min} / \mathrm{g}$ lactose $)$ an increase in 555 the temperature has little impact on the volumetric composition of these two gases 556 regardless of the lactose concentration and pressure. Exceptionally, for a $10 \mathrm{wt} . \%$ 557 lactose solution at low pressure (38 bar), a substantial increase in the proportion of $\mathrm{H}_{2}$ 558 occurs. The sharp increase in the CC sol obtained at 38 bar using a $10 \mathrm{wt} . \%$ lactose 559 might account for this development, as most of the carbon in the feed is transformed to 560 solid, which results in a gas with a higher $\mathrm{H}_{2}$ content.

562 Conversely, for a $\mathrm{W} / \mathrm{m}_{\text {lactose }}$ ratio of $40 \mathrm{~g}$ catalyst $\mathrm{min} / \mathrm{g}$ lactose two trends are observed 563 depending on the lactose concentration. For a 1 wt.\% lactose solution, an increase in the 564 temperature from 200 to $220{ }^{\circ} \mathrm{C}$ decreases the proportion of $\mathrm{H}_{2}$ in the gas regardless of 565 the pressure. An increase in the $\mathrm{W} / \mathrm{m}_{\text {lactose }}$ ratio increases $\mathrm{H}_{2}$ generation by reforming. 566 Between 200 and $220^{\circ} \mathrm{C}$ the proportions of monohydric and polyhydric alcohols in the 567 liquid increase dramatically, which is accounted for by a greater spread of $\mathrm{H}_{2}$ reactions 568 which increase the consumption of $\mathrm{H}_{2}$ [25]. Conversely, for a 10 wt.\% solution this 569 same increase in temperature does not modify the proportion of $\mathrm{H}_{2}$ in the gas, while the 570 increase observed in the proportion of $\mathrm{CO}_{2}$ still takes place, although milder than that 571 occurring for a $1 \mathrm{wt} . \%$ lactose solution. Hydrogen solubility increases with pressure, 572 thus hydrogenation reactions in the liquid phase may be more favoured. The higher the 
573 lactose concentration, the lower the amount of water and consequently the higher is the

574 partial pressure of $\mathrm{H}_{2}$ [25]. A further increase in the temperature from 220 to $240{ }^{\circ} \mathrm{C}$

575 results in a substantial increase in the $\mathrm{H}_{2}$ concentration regardless of the lactose

576 concentration and pressure. The $\mathrm{H}_{2}$ solubility in the liquid phase decreases with the

577 temperature, diminishing the extent of the hydrogenation reactions, thus augmenting the

578 proportion of $\mathrm{H}_{2}$ in the gas especially between 220 and $240{ }^{\circ} \mathrm{C}$ [37]. In addition, the

579 reforming reactions are endothermic while the WGS reaction is exothermic, which also

580 results in an increase in $\mathrm{H}_{2}$ with the temperature $[13,17]$.
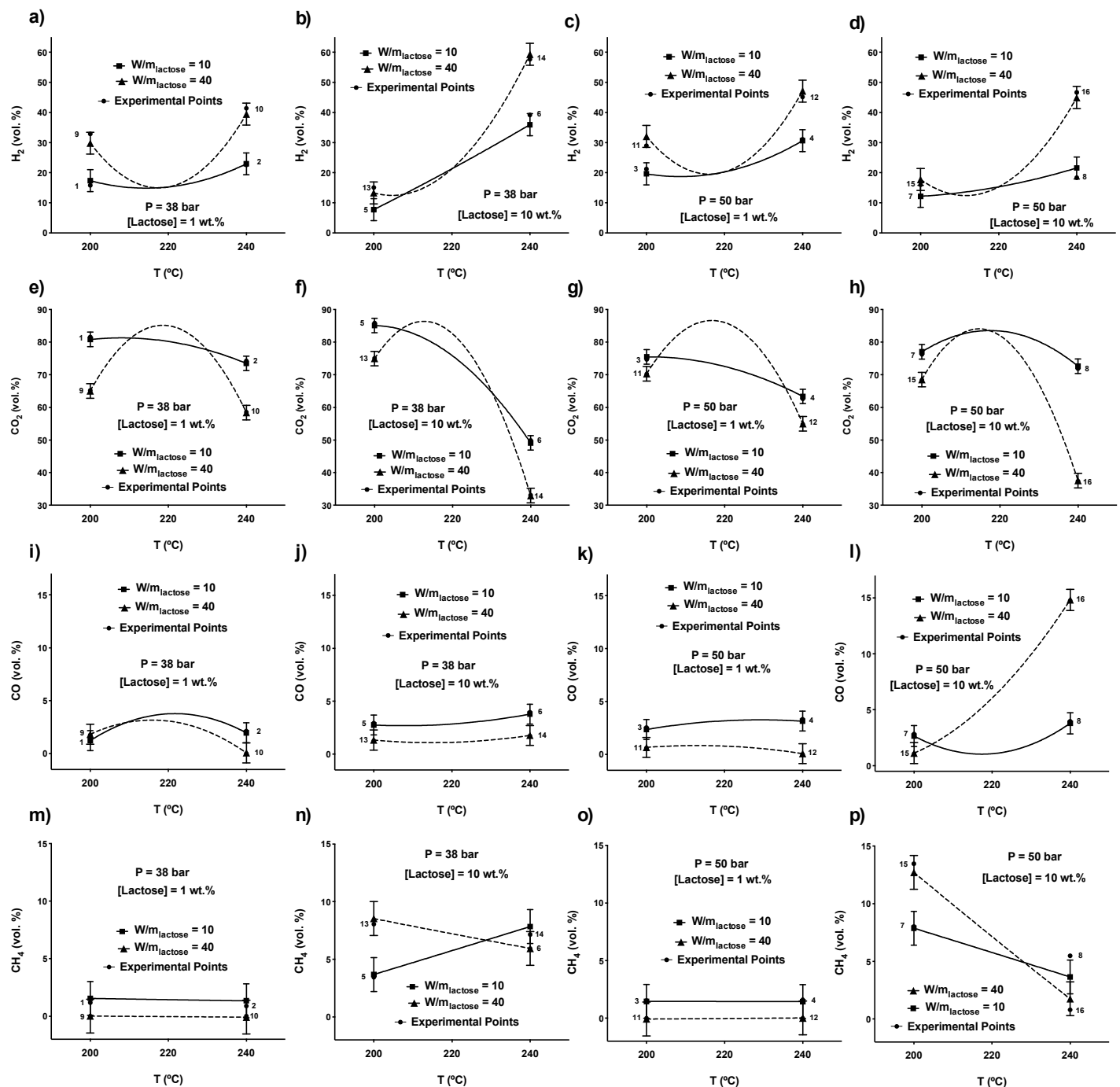

Figure 3. Interaction plots for initial relative amounts (vol.\%) of $\mathrm{H}_{2}$ (a-d), $\mathrm{CO}_{2}(\mathrm{e}-\mathrm{h}) \mathrm{CO}$ (i-l) and $\mathrm{CH}_{4}(\mathrm{~m}-$

p) in the gas. Bars are LSD intervals with $95 \%$ confidence. 
587 The $\mathrm{W} / \mathrm{m}_{\text {lactose }}$ ratio exerts a significant effect on the concentrations of $\mathrm{H}_{2}$ and $\mathrm{CO}_{2}$

588 between 200 and $215^{\circ} \mathrm{C}$ and 225 to $240^{\circ} \mathrm{C}$. This effect depends on the concentration of

589 lactose in the feed. For a $1 \mathrm{wt} . \%$ lactose solution, an increase in the $\mathrm{W} / \mathrm{m}_{\text {lactose }}$ ratio from

59010 to $40 \mathrm{~g}$ catalyst $\mathrm{min} / \mathrm{g}$ lactose results in an increase in the proportion of $\mathrm{H}_{2}$. An

591 increase in the $\mathrm{W} / \mathrm{m}_{\text {lactose }}$ ratio favours reforming reactions, increasing $\mathrm{H}_{2}$ production

592 [25]. For a $10 \mathrm{wt} . \%$ lactose solution, the effect of the $\mathrm{W} / \mathrm{m}_{\text {lactose }}$ ratio is only significant

593 between 225 and $240{ }^{\circ} \mathrm{C}$. Within this temperature range, an increase in the amount of

594 catalyst leads to an increase in the proportions of $\mathrm{H}_{2}$ due to the positive kinetic effect of

595 the catalyst on the reforming reactions together with the decrease in the $\mathrm{H}_{2}$ solubility

596 with temperature. At low temperature, the compensation between $\mathrm{H}_{2}$ production and $\mathrm{H}_{2}$

597 consumption in hydrogenation reactions accounts for the negligible effect of the

$598 \mathrm{~W} / \mathrm{m}_{\text {lactose }}$ ratio.

599

600 The effect of the concentration of lactose in the feed on the proportion of $\mathrm{H}_{2} / \mathrm{CO}_{2}$ in the

601 gas can be gathered comparing Figures 3 a/e with b/f at 38 bar and Figures 3 c/g with

$602 \mathrm{~d} / \mathrm{h}$ at 50 bar. This comparison reveals that the effect of the lactose concentration

603 depends on the temperature and pressure. Between 200 and $220{ }^{\circ} \mathrm{C}$ the concentration of

604 lactose exerts a weak impact on the proportions of these two gases. Conversely,

605 between 220 and $240{ }^{\circ} \mathrm{C}$ the concentration of lactose substantially influences the

606 proportions of $\mathrm{H}_{2}$ and $\mathrm{CO}_{2}$ in the gas. At 38 bar, a sharp increase in the proportion of $\mathrm{H}_{2}$

607 takes place due to the increase in the partial pressure of the reagents inside the reactor

608 [25]. At 50 bar the effect of the lactose concentration depends on the $\mathrm{W} / \mathrm{m}_{\text {lactose }}$ ratio.

609 For $10 \mathrm{~g}$ catalyst $\mathrm{min} / \mathrm{g}$ lactose, an increase in the lactose content from 1 to $10 \mathrm{wt} . \%$

610 very slightly decreases and increases the proportions of $\mathrm{H}_{2}$ and $\mathrm{CO}_{2}$, respectively,

611 probably due to the increase in char formation. An increase in the $\mathrm{W} / \mathrm{m}_{\text {lactose }}$ ratio lowers 
612 the effect of the lactose concentration on the relative amount of $\mathrm{H}_{2}$. As a result, the

613 effect of the lactose concentration on the proportion of $\mathrm{H}_{2}$ for a $\mathrm{W} / \mathrm{m}_{\text {lactose }}$ ratio of $40 \mathrm{~g}$

614 catalyst $\mathrm{min} / \mathrm{g}$ lactose is not significant, while the proportion of $\mathrm{CO}_{2}$ decreases slightly

615 between 230 to $240{ }^{\circ} \mathrm{C}$. Under these conditions the decrease in the proportion of $\mathrm{CO}_{2}$ is

616 the consequence of the increase observed in the proportion of $\mathrm{CO}$ in the gas.

618 A comparison between Figures $3 \mathrm{a} / \mathrm{e}$ and $\mathrm{b} / \mathrm{f}$ with $3 \mathrm{c} / \mathrm{g}$ and $\mathrm{d} / \mathrm{h}$ shows the effect of the

619 total pressure on the proportion of $\mathrm{H}_{2} / \mathrm{CO}_{2}$ in the gas when lactose solutions of 1 and 10

620 wt.\% are fed, respectively. This comparison reveals that the effect of the pressure

621 depends on the concentration of lactose. For a $1 \mathrm{wt} . \%$ lactose solution and $10 \mathrm{~g}$ catalyst

$622 \mathrm{~min} / \mathrm{g}$ lactose, an increase in the total pressure from 38 to 50 bar does not greatly

623 modify the proportions of $\mathrm{H}_{2}$ and $\mathrm{CO}_{2}$ in the gas. Conversely, for $40 \mathrm{~g}$ catalyst $\mathrm{min} / \mathrm{g}$

624 lactose, this increase in pressure slightly increases the proportion of $\mathrm{CO}_{2}$ between 200

625 and $220{ }^{\circ} \mathrm{C}$; the effect of the pressure being insignificant from 220 to $240{ }^{\circ} \mathrm{C}$. For a 10

626 wt.\% lactose solution the effect of the pressure depends on the reaction temperature.

627 The pressure does not exert a great impact between 200 and $220^{\circ} \mathrm{C}$, while the

628 proportions of these two gases are greatly modified with varying the system pressure

629 when a temperature between 220 and $240{ }^{\circ} \mathrm{C}$ is used. From 220 to $240{ }^{\circ} \mathrm{C}$, an increase in

630 pressure from 38 to 50 bar leads to a decrease in the relative amount of $\mathrm{H}_{2}$ when using a

$631 \mathrm{~W} / \mathrm{m}_{\text {lactose }}$ ratio of $10 \mathrm{~g}$ catalyst $\mathrm{min} / \mathrm{g}$ lactose. In addition, these variations depend on the

$632 \mathrm{~W} / \mathrm{m}_{\text {lactose }}$ ratio; the lower the ratio, the greater are the variations in the proportions of $\mathrm{H}_{2}$

633 and $\mathrm{CO}_{2}$. An increase in pressure produces an increase in the partial pressure of the

634 reagents inside the reactor, which promotes their transformation into gases [25] due to

635 an increase in the rate of $\mathrm{C}-\mathrm{C}$ bond cleavage reactions [52] favouring $\mathrm{H}_{2}$ production. 
638 The effect of the operating variables on the proportions of $\mathrm{CO}$ and $\mathrm{CH}_{4}$ is weak and the

639 relative amounts of these two gases during the first hour of reaction are lower than 15

640 vol.\%. Under the temperatures studied in this work, the water gas shift (WGS) reaction

641 is shifted towards $\mathrm{H}_{2}$ and $\mathrm{CO}_{2}$, which explains the low proportion of $\mathrm{CO}$ in the gas. The

642 effect of the temperature on the proportion of $\mathrm{CO}$ depends on the pressure and the

$643 \mathrm{~W} / \mathrm{m}_{\text {lactose }}$ ratio. In general the effect of the temperature on the proportion of $\mathrm{CO}$ in the

644 gas is very weak. At 38 bar, the temperature does not influence the proportion of $\mathrm{CO}$ in

645 the gas, which is lower than 4 vol.\% regardless of the $\mathrm{W} / \mathrm{m}_{\text {lactose }}$ ratio and the lactose

646 concentration. At 50 bar, the effect of the temperature is only significant when feeding a

$64710 \mathrm{wt} . \%$ lactose solution using a $\mathrm{W} / \mathrm{m}_{\text {lactose }}$ ratio of $40 \mathrm{~g}$ catalyst $\mathrm{min} / \mathrm{g}$ lactose. Under

648 these conditions an increase in temperature increases the proportion of $\mathrm{CO}$ in the gas

649 very sharply, which could indicate that decarbonylation reactions are intensified under

650 these operating conditions [25].

651

652 The effect of the $\mathrm{W} / \mathrm{m}_{\text {lactose }}$ ratio on the proportion of $\mathrm{CO}$ depends on the pressure and

653 lactose concentration. At low pressure (38 bar), an increase from 10 to $40 \mathrm{~g}$ catalyst

$654 \mathrm{~min} / \mathrm{g}$ lactose does not modify the relative amount of CO in the gas. Conversely, at 50

655 bar, this same increase leads to a small decrease in the proportion of CO when feeding a

$6561 \mathrm{wt} . \%$ lactose solution, while a sharp increase is observed for a $10 \mathrm{wt} . \%$ lactose

657 solution as explained above. The effects of the pressure and the lactose concentration on

658 the proportion of $\mathrm{CO}$ in the gas are negligible, as $\mathrm{CO}$ formation is not

659 thermodynamically favoured at temperatures lower than $240{ }^{\circ} \mathrm{C}$. 
661 The effect of the temperature on the proportion of $\mathrm{CH}_{4}$ in the gas depends on the

662 concentration of lactose, pressure and $\mathrm{W} / \mathrm{m}_{\text {lactose }}$ ratio. Specifically, the temperature does

663 not significantly influence the proportion of $\mathrm{CH}_{4}$ for a diluted lactose solution (1 wt.\%),

664 while it exerts a moderate influence for a $10 \mathrm{wt} . \%$ lactose solution. For a $10 \mathrm{wt} . \%$

665 solution the effect of the temperature depends on the pressure and the $\mathrm{W} / \mathrm{m}_{\text {lactose }}$ ratio.

666 At 38 bar, an increase in the reaction temperature increases the proportion of $\mathrm{CH}_{4}$ for a

667 low $\mathrm{W} / \mathrm{m}_{\text {lactose }}$ ratio, while this increase in temperature decreases the relative amount of

$668 \mathrm{CH}_{4}$ for a high $\mathrm{W} / \mathrm{m}_{\text {lactose }}$ ratio. At 50 bar, an increase in temperature leads to a decrease

669 in the proportion of $\mathrm{CH}_{4}$ in the gas regardless of the $\mathrm{W} / \mathrm{m}_{\text {lactose }}$ ratio. The decreases in

670 the proportion of $\mathrm{CH}_{4}$ in the gas are the consequence of the endothermic nature of the

671 methane reforming reaction [14] which is thermodynamically favoured at high

672 temperatures and kinetically promoted using a high $\mathrm{W} / \mathrm{m}_{\text {lactose }}$ ratio.

673

674 As a result of the dependence of the effect of the temperature with the lactose

675 concentration and the $\mathrm{W} / \mathrm{m}_{\text {lactose }}$ ratio, the effect of the $\mathrm{W} / \mathrm{m}_{\text {lactose }}$ ratio is only significant

676 for a $10 \mathrm{wt} . \%$ lactose solution. The lower excess of water for a concentrated lactose

677 solution reduces the development of the methane reforming reactions, increasing the

678 proportion of $\mathrm{CH}_{4}$ in the gas [57-61]. For a concentrated solution, an increase in this

679 ratio (from 10 to $40 \mathrm{~g}$ catalyst $\mathrm{min} / \mathrm{g}$ lactose) increases the proportion of $\mathrm{CH}_{4}$ in the gas

680 between 200 and $220^{\circ} \mathrm{C}$, as methanation is favoured within this temperature range [25].

681 The effect of the total pressure is only significant for a $10 \mathrm{wt} . \%$ lactose solution.

682 Between 200 and $220^{\circ} \mathrm{C}$ an increase in pressure leads to an increase in the proportion of

$683 \mathrm{CH}_{4}$ in the gas, while a further increase up to $240{ }^{\circ} \mathrm{C}$ reduces the relative amount of this 684 gas. 
687 Figure S4 summarises the relative amount of each of the different families of liquid 688 compounds for the different experiments represented in 3 intervals of 60 minutes each.

689 The liquid phase is made up of a mixture of aldehydes, carboxylic acids, alcohols, 690 ketones and furans in water. Acetaldehyde is the most abundant compound for the 691 aldehydes, while the carboxylic acids are mainly made up of acetic and propionic acids 692 and, in a lower proportion, pentanoic acids. Alcohols include monohydric alcohols 693 (mainly methanol and ethanol, and in lower proportions 1-butanol, 2-butanol, 1694 pentanol and 2-pentanol), polyhydric alcohols (1,2-propanediol, 1,2-ethanediol, 2,3695 butanediol) and, in lower proportions, monohydric substituted (2-methyl-3-pentanol) 696 and alicyclic alcohols (2-furanmethanol). Ketones include C3-ketones such as 2697 propanone (acetone) and 2-propanone-1-hydroxy, C4-ketones (2-butanone-3-hydroxy 698 and 2-butanone-1-hydroxy, 2,3-butanedione and 2 butanone) and small amounts of 699 cyclic ketones (cyclopentanone and cyclohexanone) and furanic ketones (2-hydroxygamma-butyrolactone). Furans comprise furfural, 5-hydroxymethyl-2-

701 furancaboxaldehyde and 5-methyl-2-furancaboxaldehyde. The presence of these 702 compounds in the condensates is consistent with the pathway proposed in Figure 1 and 703 those proposed by several authors studying the APR of polyols and sugar based 704 compounds $[13,14,19-23,27-33,36-39,41,42,54,62,63]$.

The statistical analysis reveals significant differences $(p$-values $<0.005)$ in the relative amounts of these compounds in the liquid phase. The results of the Fisher's LSD test

708 are plotted in Figure S4. The relative concentration for the most abundant compounds, expressed as relative chromatographic area, varies as follows. Aldehydes: $0-11 \%$, carboxylic acids: 0-22\%, monohydric alcohols: $0-23 \%$, polyhydric-alcohols: $0-48 \%$, 
711 C3-ketones: 4-100\%, C4-ketones: 0-18\%, cyclic-ketones: $0-15 \%$ and furans: $0-85 \%$.

712 Increases and decreases in the proportions of these families with time are detected.

713 Carboxylic acids, monohydric alcohols and C3 and C4 ketones display increases and

714 decreases over time. Aldehydes and cyclic ketones mostly show decreases, while 715 increases are mainly observed for furans. These variations have been analysed with the

716 multivariate Spearman's. The multivariate analysis reveals significant relationships for

717 the proportion of $\mathrm{C} 3$-ketones with the proportions of monohydric alcohols ( $\mathrm{p}$-value $=$

$\left.7180.0001 ; \mathrm{R}^{2}=0.55\right)$ and carboxylic acids $\left(\mathrm{p}\right.$-value $\left.=0.0215 ; \mathrm{R}^{2}=0.24\right) ;$ and between the

719 proportion of cyclic ketones and the proportions of C4-ketones ( $\mathrm{p}$-value $=0.0001 ; \mathrm{R}^{2}=$

$7200.41)$ and aldehydes ( $p$-value $=0.0001 ; \mathrm{R}^{2}=0.56$ ). In addition, the proportion of furans

721 depends on the proportion of carboxylic acids ( $\mathrm{p}$-value $=0.0001 ; \mathrm{R}^{2}=0.42$ ). These

722 relationships can explain most of the variations of the liquid phase composition and 723 confirm the pathway shown in Figure 1.

724

725 Table S4 shows the significant terms in the codec model and their relative influence in 726 the process according to the ANOVA analysis for the proportions of the most abundant

727 families of compounds present in the liquid phase during the first hour of reaction:

728 aldehydes, carboxylic acids, monohydric and polyhydric alcohols, ketones (C3, C4 and

729 cyclic) and furans. The interactions of the temperature with the $\mathrm{W} / \mathrm{m}_{\text {lactose }}$ ratio and

730 lactose concentration with the $\mathrm{W} / \mathrm{m}_{\text {lactose }}$ ratio greatly influence the composition of

731 aldehydes in the liquid. Carboxylic acids are influenced by the pressure and the

732 interactions of temperature with both the lactose concentration ( $\mathrm{TC}$ and $\mathrm{T}^{2} \mathrm{C}$ ) and the

733 pressure $\left(\mathrm{T}^{2} \mathrm{P}\right)$. The interactions of the temperature with the lactose concentration $\left(\mathrm{T}^{2} \mathrm{C}\right)$

734 and with the system pressure $\left(\mathrm{T}^{2} \mathrm{P}^{2}\right)$ are the major factors responsible for the evolution

735 of the proportions of monohydric and polyhydric alcohols. In addition, polyhydric 
736 alcohols are greatly influenced by the temperature $\left(\mathrm{T}^{2}\right)$. The pressure $\left(\mathrm{P}^{2}\right)$ and the

737 interaction of the temperature with the lactose concentration $\left(\mathrm{T}^{2} \mathrm{C}\right)$ have a high impact

738 on the proportion of C3-ketones, while C4-ketones mainly depend on the interactions

739 between the temperature, pressure, lactose concentration and $\mathrm{W} / \mathrm{m}_{\text {lactose }}$ ratio (TPC and

740 TCW). Cyclic ketones are strongly influenced by the lactose concentration and its

741 interaction with the temperature and pressure (TPC). Many different interactions

742 between the operating variables influence the proportion of furans in the liquid.

744 Figures 4 and 5 illustrate the effect of these interactions according to the ANOVA

745 analysis for the relative amounts of the most abundant compounds present in the liquid

746 phase. Figure 4 displays these effects for the proportions of carboxylic acids,

747 monohydric and polyhydric alcohols, and aldehydes, while Figure 5 shows these effects

748 for the proportions of C3, C4 and cyclic ketones and furans. Specifically, the effects of

749 the reaction temperature, employing a pressure of 38 bar for $\mathrm{W} / \mathrm{m}_{\text {lactose }}$ ratios of 10 and

$75040 \mathrm{~g}$ catalyst $\mathrm{min} / \mathrm{g}$ lactose, feeding lactose concentrations of 1 and $10 \mathrm{wt} . \%$, are shown

751 in Figures 4 and $5 \mathrm{a}$ and b, e and $\mathrm{f}, \mathrm{i}$ and $\mathrm{j}$, and $\mathrm{m}$ and $\mathrm{n}$. Figures 4 and $5 \mathrm{c}$ and $\mathrm{d}, \mathrm{g}$ and

$752 \mathrm{~h}, \mathrm{k}$ and $\mathrm{l}$, and $\mathrm{o}$ and $\mathrm{p}$ display the effects of the temperature and the $\mathrm{W} / \mathrm{m}_{\text {lactose }}$ ratio

753 employing a pressure of 50 bar when lactose solutions of 1 and $10 \mathrm{wt} . \%$ were used,

754 respectively. 

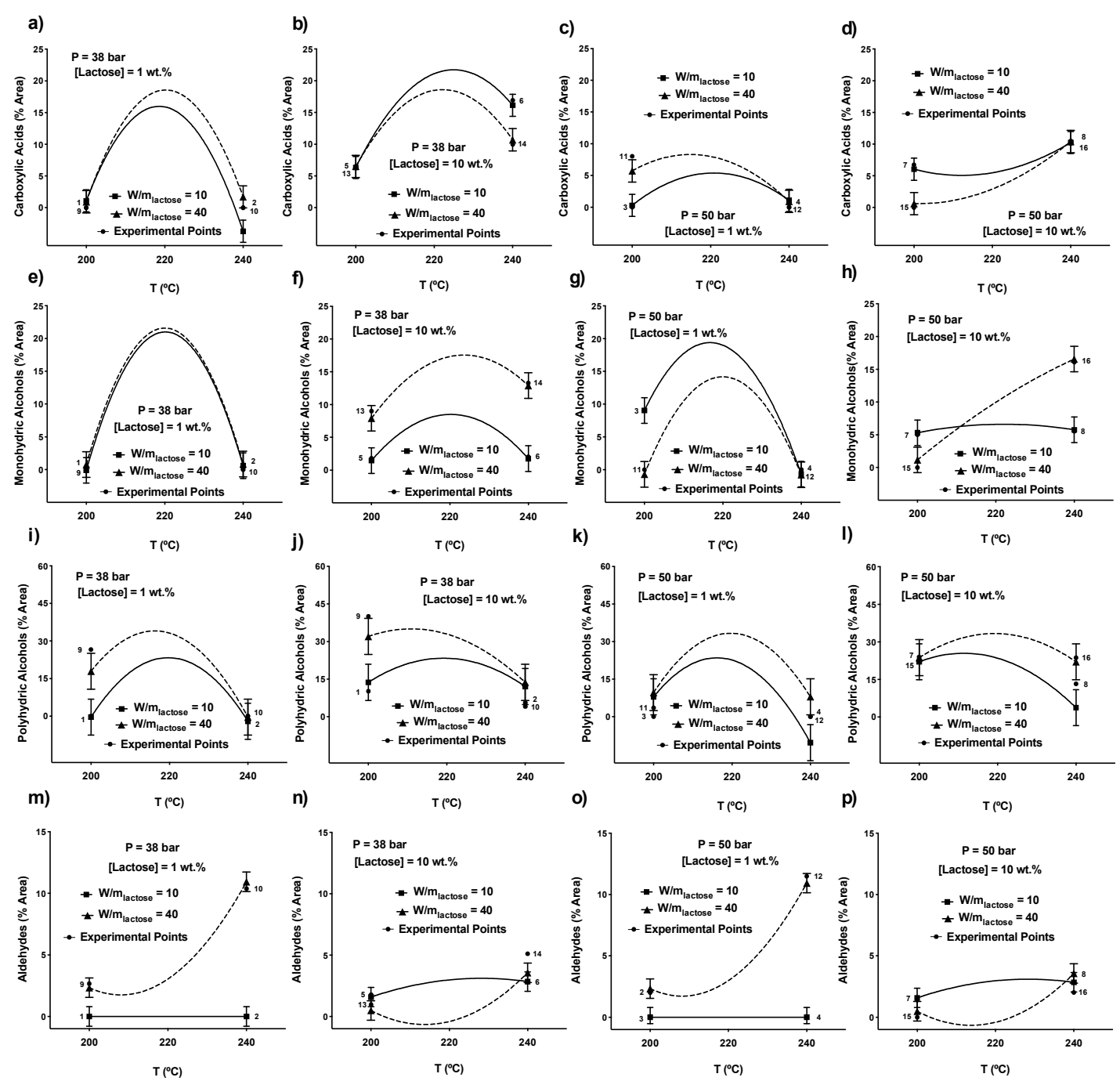

Figure 4. Interaction plots for the relative amounts in the liquid of carboxylic acids (a-d), monohydric alcohols (e-h), polyhydric alcohols (i-1) and aldehydes (m-p). Bars are LSD intervals with 95\%

761 confidence.

\subsubsection{Carboxylic acids}

764 Acetic and propionic acids are the most abundant carboxylic acids in the liquid phase.

765 Propionic acid formation occurs to a lesser extent due to the higher proportion of 1-

766 hydroxypropan-2-one hydrogenated compounds than dehydrated compounds in the

767 liquid. Acetic acid is mainly responsible for the variations observed in the proportion of

768 carboxylic acids during the first hour of reaction (Figures 4 a-d). Acetic acid is obtained

769 in the final steps of routes A and B. The temperature exhibits two different effects on 
770 the proportion of carboxylic acids depending on the pressure. At 38 bar an increase in

771 the temperature leads to an initial increase in the proportion of carboxylic acids from

772200 to $220^{\circ} \mathrm{C}$ followed by a substantial decrease between 220 and $240{ }^{\circ} \mathrm{C}$. In addition,

773 this latter depletion strongly depends on the concentration of lactose in the feed; the

774 lower the concentration of lactose, the sharper is the decrease observed. The

775 temperature exerts a positive catalytic effect on the process. Therefore, between 200 and

$776220^{\circ} \mathrm{C}$, an increase in temperature helps the formation of liquid end products. A further

777 increase in temperature might shift their decomposition to gases. In addition, high

778 temperatures can also partially hinder acetic acid formation as the solubility of $\mathrm{H}_{2}$ in

779 water decreases with temperature. Conversely, at 50 bar the temperature exerts a weaker

780 effect on the relative amount of carboxylic acids. This increase in pressure kinetically

781 enhances the acetic acid decomposition rate [25]. This effect depends on the lactose

782 concentration. For a 1 wt.\% lactose solution a mild increase with temperature occurs

783 between 200 and $220^{\circ} \mathrm{C}$, followed by a small decrease from 220 to $240{ }^{\circ} \mathrm{C}$. However,

784 this evolution with temperature is not as pronounced as it is at 38 bar. For a 10 wt.\%

785 lactose solution, the effect of the temperature is negligible between 200 and $220{ }^{\circ} \mathrm{C}$,

786 while a small increase takes place with a further increase in the temperature up to 240

$787{ }^{\circ} \mathrm{C}$

788

789 The effect of the $\mathrm{W} / \mathrm{m}_{\text {lactose }}$ on the proportion of carboxylic acids depends on the

790 concentration of lactose, the temperature and the pressure. At 38 bar the $\mathrm{W} / \mathrm{m}_{\text {lactose }}$ ratio

791 does not significantly influence the proportion of carboxylic acids between 200 and 220

$792{ }^{\circ} \mathrm{C}$ regardless of the lactose concentration. Within this temperature range, the positive 793 kinetic effect of the temperature can mask the effect of the $\mathrm{W} / \mathrm{m}_{\text {lactose }}$ ratio on the 794 process and the lowest $\mathrm{W} / \mathrm{m}_{\text {lactose }}$ ratio used in this work (10 $\mathrm{g}$ catalyst $\mathrm{min} / \mathrm{g}$ lactose $)$ 
795 might be sufficient to achieve high concentrations of acetic acid in the liquid. Between 796220 and $240{ }^{\circ} \mathrm{C}$ an increase in the $\mathrm{W} / \mathrm{m}_{\text {lactose }}$ ratio results in an increase in the proportion 797 of this family of compounds for a $1 \mathrm{wt} . \%$ lactose solution, while a decrease is observed 798 for $10 \mathrm{wt} . \%$. An increase in the amount of catalyst promotes acetic acid production, 799 which accounts for the increase observed. However, an increase in the concentration of 800 lactose in the solution also increases the partial pressure of acetic acid inside the reactor, 801 which kinetically favours its decomposition to gases [25]. At 50 bar, the opposite effect 802 is observed. For a diluted lactose solution, an increase in the $\mathrm{W} / \mathrm{m}_{\text {lactose }}$ ratio promotes 803 acetic acid formation, while for a concentrated solution it favours its decomposition due 804 to the increase in the partial pressure of the liquid intermediates [25]. In addition, the 805 increase observed in the proportion of carboxylic acids takes places along with a 806 decrease in C3-ketones, and vice versa. The greatest effect of the pressure on the 807 proportion of carboxylic acids takes place between 220 to $240{ }^{\circ} \mathrm{C}$. An increase in the 808 pressure from 38 to 50 bar leads to a decrease in the proportion of carboxylic acids due 809 to the positive kinetic effect of this variable for acetic acid decomposition [25].

\subsubsection{Alcohols: monohydric and polyhydric alcohols}

812 The variations in the relative amount of monohydric alcohols basically correspond to

813 variations in methanol and ethanol, while the variations observed for polyhydric

814 alcohols are accounted for by variations in the proportions of 1,2-propane-diol and 1,2-

815 ethane-diol. The temperature has different influences on the proportion of monohydric

816 and polyhydric alcohols depending on the lactose concentration, pressure and $\mathrm{W} / \mathrm{m}_{\text {lactose }}$ 817 ratio, due to the large number of interactions detected between these variables. 
819 For a diluted lactose solution ( $1 \mathrm{wt.} \%)$, an initial increase in the temperature from 200 to

$820220^{\circ} \mathrm{C}$ leads to an initial increase in the proportion of monohydric and polyhydric

821 alcohols. The proportions of both families of alcohols decrease when the temperature is

822 further increased up to $240{ }^{\circ} \mathrm{C}$ regardless of the pressure and $\mathrm{W} / \mathrm{m}_{\text {lactose }}$ ratio. In

823 addition, the increase and the decrease observed for the proportion of monohydric

824 alcohols are sharper than for polyhydric alcohols. The temperature exerts a positive

825 kinetic effect on lactose decomposition, which favours the production of liquid end

826 products [25]. These results suggest that routes A and B are prevalent over route C

827 between 200 and $220^{\circ} \mathrm{C}$. This is in good agreement with the results from other works

828 that report that sugar dehydration to produce furanic compounds is preferential at high

829 temperatures $[27,28,31,33]$. A further increase in the temperature from 220 to $240{ }^{\circ} \mathrm{C}$

830 helps the transformation of monohydric and polyhydric alcohols to gases $[37,52,54$,

$83164,65]$. In addition, high temperatures also potentiate dehydration reactions from

832 lactose $[27,28,31,33]$. This leads to the formation of furan compounds, which favours

833 route $\mathrm{C}$ over $\mathrm{A}$ and $\mathrm{B}$.

834

835 For a $10 \mathrm{wt} . \%$ lactose solution, the effect of the temperature depends on the pressure

836 and $\mathrm{W} / \mathrm{m}_{\text {lactose }}$ ratio. At 38 bar, an increase in temperature between 200 and $220{ }^{\circ} \mathrm{C}$

837 increases the proportion of monohydric alcohols without significantly modifying the

838 relative amount of polyhydric alcohols in the liquid regardless of the $\mathrm{W} / \mathrm{m}_{\text {lactose }}$ ratio. A

839 further increase up to $240{ }^{\circ} \mathrm{C}$ results in a decrease in the proportion of monohydric

840 alcohols irrespective of the $\mathrm{W} / \mathrm{m}_{\text {lactose }}$ ratio and in a decrease in the relative amount of

841 polyhydric alcohols only when the highest $\mathrm{W} / \mathrm{m}_{\text {lactose }}$ ratio is used. An increase in the

842 lactose concentration favours the advancement of the reactions in the liquid phase [25].

843 As a result, a lower temperature is required to achieve the highest proportion of 
844 polyhydric alcohols when the highest $\mathrm{W} / \mathrm{m}_{\text {lactose }}$ is used for a $10 \mathrm{wt} \% \%$ than for a $1 \mathrm{wt} . \%$

845 lactose solution. In addition, an increase in the concentration of lactose produces a

846 greater spread of sugar dehydration reactions towards furanic compounds [28]. This

847 development produces a competition between routes $\mathrm{A}$ and $\mathrm{B}$ and route $\mathrm{C}$. Therefore, a

848 greater amount of catalyst is needed to produce the end products obtained from routes A

849 and B.

850

851 At 50 bar two different trends are observed depending on the $\mathrm{W} / \mathrm{m}_{\text {lactose }}$ ratio for a 10

852 wt.\% lactose solution. When using a $\mathrm{W} / \mathrm{m}_{\text {lactose }}$ ratio of $10 \mathrm{~g}$ catalyst $\mathrm{min} / \mathrm{g}$ lactose, an

853 increase in the temperature does not significantly modify the proportion of monohydric

854 alcohols but slightly decreases the proportion of polyhydric alcohols. High temperature

855 and pressure favours dehydration reactions from sugars [27, 28, 31, 33], and therefore a

856 low proportion of liquid end products obtained via routes A and B is achieved.

857 Conversely, for $40 \mathrm{~g}$ catalyst $\mathrm{min} / \mathrm{g}$ lactose, this increment in the temperature produces a

858 sharp increase in the proportion of monohydric alcohols, without greatly modifying the

859 proportion of polyhydric alcohols. This might account for the increase in the

860 concentration of end products obtained from routes A and B.

862 The pressure exerts a weaker effect on the proportions of monohydric and polyhydric

863 alcohols than the temperature. The variations observed for the proportion of

864 monohydric alcohols are relatively low when the system pressure increases from 38 to

86550 bar, while variations in polyhydric alcohols are not important from a practical point

866 of view. The variations observed for monohydric alcohols depend on the lactose

867 concentration. On the one hand, when a diluted lactose solution (1 wt.\%) is fed, an

868 increase in pressure from 38 to 50 bar slightly increases the proportion of monohydric 
869 alcohols between 200 and $215^{\circ} \mathrm{C}$ when a $\mathrm{W} / \mathrm{m}_{\text {lactose }}$ ratio of $10 \mathrm{~g}$ catalyst $\mathrm{min} / \mathrm{g}$ lactose

870 is used. Within this range, an increase in pressure increases the development of the

871 reaction leading to the formation of liquid end products. This effect is only significant

872 for a low $\mathrm{W} / \mathrm{m}_{\text {lactose }}$ ratio, as the positive kinetic effect of the catalyst can compensate for

873 the lower amount of catalyst used, thus masking the effect of the pressure for high

$874 \mathrm{~W} / \mathrm{m}_{\text {lactose }}$ ratios. Conversely, for $40 \mathrm{~g}$ catalyst $\mathrm{min} / \mathrm{g}$ lactose, this increase in pressure

875 decreases the proportion of monohydric alcohols between 210 and $230{ }^{\circ} \mathrm{C}$. This

876 increase in pressure kinetically enhances the decomposition of monohydric alcohols

877 when a high amount of catalyst is used [25]. On the other hand, for a $10 \mathrm{wt} . \%$ lactose

878 solution, the effect of the pressure is relatively weak for $10 \mathrm{~g}$ catalyst $\mathrm{min} / \mathrm{g}$ lactose,

879 while a moderate decrease in the proportion of monohydric alcohols is observed for 40

$880 \mathrm{~g}$ catalyst $\mathrm{min} / \mathrm{g}$ lactose between 200 and $230{ }^{\circ} \mathrm{C}$.

881

882 The effect of the $\mathrm{W} / \mathrm{m}_{\text {lactose }}$ ratio is relatively weak and depends on the pressure and

883 lactose concentration. At 38 bar, an increase in the $\mathrm{W} / \mathrm{m}_{\text {lactose }}$ ratio from 10 to $40 \mathrm{~g}$

884 catalyst min/g lactose does not modify the proportion of monohydric alcohols when a

885 diluted solution is used (1wt.\%). Conversely, an increase in the lactose concentration

886 makes the effect of the $\mathrm{W} / \mathrm{m}_{\text {lactose }}$ ratio significant, increasing the proportions of

887 monohydric alcohols in the liquid. An increase in the lactose concentration makes route

$888 \mathrm{C}$ prevalent over $\mathrm{A}$ and $\mathrm{B}$, as explained above. This increase in the $\mathrm{W} / \mathrm{m}_{\text {lactose }}$ ratio

889 increases the proportion of polyhydric alcohols between 200 and $220^{\circ} \mathrm{C}$ regardless of

890 the lactose concentration due to the positive kinetic effect of the catalyst, which favours

891 lactose decomposition. At 50 bar an increase in the $\mathrm{W} / \mathrm{m}_{\text {lactose }}$ ratio decreases the

892 proportion of monohydric alcohols between 200 and $220^{\circ} \mathrm{C}$ for a $1 \mathrm{wt} . \%$ lactose

893 solution. This depletion occurs along with an increase in the proportions of aldehydes 
894 and carboxylic acids in the liquid. Increases in the proportion of acetaldehyde and acetic

895 acid are accounted for by these variations. The positive catalytic effect of the pressure

896 and $\mathrm{W} / \mathrm{m}_{\text {lactose }}$ ratio helps shift the decomposition of monohydric alcohols to end liquids

897 and gases [25]. Conversely, an increase in this family of compounds occurs between

898220 and $240{ }^{\circ} \mathrm{C}$ when a 10 wt.\% lactose solution is fed. Dehydration reactions are

899 favoured at high temperature, pressure and using a concentrated lactose solution, which

900 makes route $\mathrm{C}$ prevalent over routes $\mathrm{A}$ and $\mathrm{B}$. Therefore, at these operating conditions

901 under which routes A and B are not predominant, it might be necessary to use a high

$902 \mathrm{~W} / \mathrm{m}_{\text {lactose }}$ ratio to produce a greater spread of the reactions leading to the formation of

903 end products obtained via routes A and B. In addition, the proportion of polyhydric

904 alcohols increases between 220 and $240{ }^{\circ} \mathrm{C}$ regardless of the lactose concentration due

905 to the positive kinetic effect of the catalyst.

906

907

\subsubsection{Aldehydes}

908 The relative amount of this compound in the liquid phase is low (0-12\%), probably 909 because it is one of the end products of lactose aqueous phase reforming and/or it can 910 easily be transformed into gas in the final steps of the process [25]. The relative amount

911 of aldehydes strongly depends on the $\mathrm{W} / \mathrm{m}_{\text {lactose }}$ ratio and the concentration of lactose in 912 the solution. Very interestingly, the pressure (between 38 and 50 bar) does not 913 significantly influence the proportion of aldehydes in the liquid. This was also reported 914 in a previous work analysing the effect of the pressure on the proportion of this family 915 of compounds during the APR of crude glycerol [25]. 
917 When a $1 \mathrm{wt} . \%$ lactose solution is fed, the liquid product has a negligible concentration 918 of aldehydes for a $\mathrm{W} / \mathrm{m}_{\text {lactose }}$ ratio of $10 \mathrm{~g}$ catalyst $\mathrm{min} / \mathrm{g}$ lactose, regardless of the

919 pressure. Conversely, a sharp increase in the proportion of aldehydes occurs when

920 increasing the temperature, especially between 220 and $240{ }^{\circ} \mathrm{C}$, for $40 \mathrm{~g}$ catalyst $\mathrm{min} / \mathrm{g}$

921 lactose within the whole interval of pressure considered (38-50 bar). This increase in the

922 proportion of aldehydes accounts for the decrease observed in the relative amount of

923 monohydric alcohols. This development indicates that the dehydration of ethane 1,2-

924 diol to acetaldehyde is more likely to occur than its hydrogenation to ethanol since at

925 high temperatures $\mathrm{H}_{2}$ solubility decreases with temperature. In addition, high

926 temperatures and $\mathrm{W} / \mathrm{m}_{\text {lactose }}$ ratios favour the advancement of the reaction in the liquid

927 phase towards the formation of liquid products. Therefore, when a diluted lactose

928 solution is fed, an increase in the $\mathrm{W} / \mathrm{m}_{\text {lactose }}$ ratio from 10 to $40 \mathrm{~g}$ catalyst $\mathrm{min} / \mathrm{g}$ lactose

929 leads to a substantial increase in the proportion of aldehydes in the liquid.

930

931

3.3.4 Ketones: C3-ketones, C4-ketones and cyclic ketones

932 The ketonic fraction is made up of ketones of three and four carbon atoms (C3-ketones

933 and C4-ketones) together with cyclic ketones and, in lower proportions, furanic ketones.

934 C3-ketones, mainly obtained from dehydration reactions, are the most abundant ketones 935 in the liquid phase. 

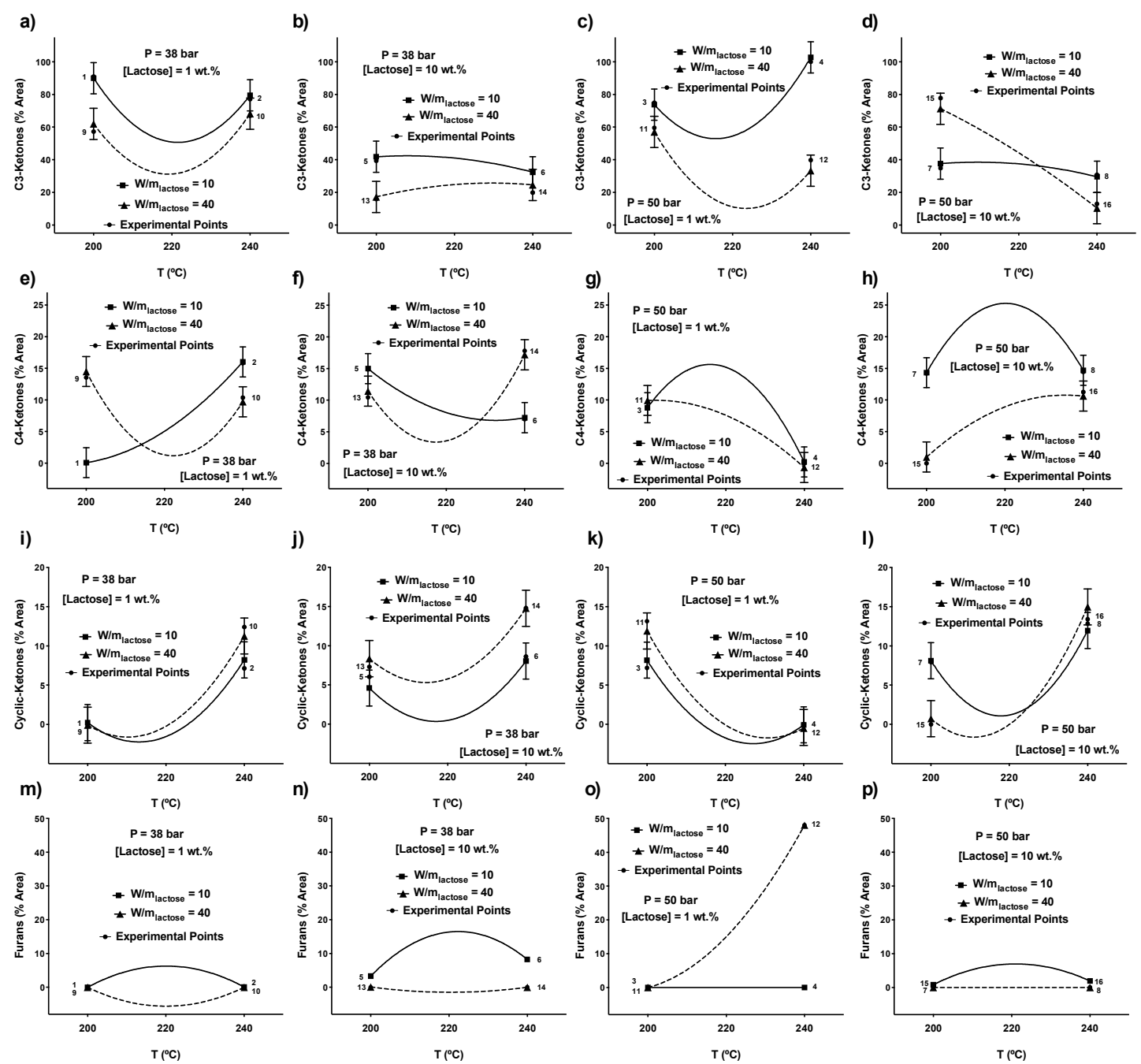

939 Figure 5. Interaction plots for the relative amounts in the liquid of C3-ketones (a-d), C4-ketones (e-h),

940 cyclic ketones (i-l) and furans (m-p). Bars are LSD intervals with $95 \%$ confidence.

942 The effect of the temperature depends on the lactose concentration and pressure. For a 1

943 wt.\% lactose solution, the proportion of C3-ketones decreases from 200 to $220{ }^{\circ} \mathrm{C}$ and

944 increases with a further increase in the temperature up to $240{ }^{\circ} \mathrm{C}$, regardless of the

945 pressure and the $\mathrm{W} / \mathrm{m}_{\text {lactose }}$ ratio. Between 200 and $220^{\circ} \mathrm{C}$ an increase in temperature

946 kinetically produces a greater spread of hydrogenation reactions in the liquid. However,

947 the $\mathrm{H}_{2}$ solubility in water decreases with a further increase in temperature up to $240{ }^{\circ} \mathrm{C}$,

948 thus hindering the hydrogenation of ketones to alcohols. This accounts for the increase

949 observed in ketones and the decreases observed in the proportions of monohydric and 
950 polyhydric alcohols [25]. For this diluted lactose solution, an increase in the $\mathrm{W} / \mathrm{m}_{\text {lactose }}$ 951 ratio from 10 to $40 \mathrm{~g}$ catalyst/min $\mathrm{g}$ lactose leads to a decrease in the proportion of C3-

952 ketones. This drop occurs between 200 and $230{ }^{\circ} \mathrm{C}$ at 38 bar and between 210 to $240{ }^{\circ} \mathrm{C}$

953 at 50 bar. These depletions account for a greater advancement of the reaction in the

954 liquid phase towards the formation of liquid products [25].

955

956 For a $10 \mathrm{wt} . \%$ lactose solution the effect of the temperature strongly depends on the

957 pressure. At 38 bar, the temperature does not significantly affect the proportion of $\mathrm{C} 3$

958 ketones in the liquid, and the $\mathrm{W} / \mathrm{m}_{\text {lactose }}$ ratio is only significant between 200 and $215^{\circ} \mathrm{C}$,

959 where an increase from 10 to $40 \mathrm{~g}$ catalyst $\mathrm{min} / \mathrm{g}$ lactose slightly decreases the relative

960 amount of C3-ketones. It is believed that the non-significant effect of the temperature is

961 the consequence of two developments. On the one hand, between 200 and $220^{\circ} \mathrm{C}$ an

962 increase in the lactose concentration increases the partial pressure of C3-ketones in the

963 liquid, favouring their transformation towards liquid end products, thus decreasing their

964 relative amount in the liquid. On the other hand, between 220 and $240{ }^{\circ} \mathrm{C}$ the formation

965 of furanic compounds from the dehydration of glucose and galactose through route $\mathrm{C}$ is

966 favoured, decreasing the proportion of C3-ketones in the liquid. At 50 bar, the effect of

967 the temperature is not significant for a low $\mathrm{W} / \mathrm{m}_{\text {lactose }}$ ratio. However, an increase in the

$968 \mathrm{~W} / \mathrm{m}_{\text {lactose }}$ ratio up to $40 \mathrm{~g}$ catalyst $\mathrm{min} / \mathrm{g}$ lactose increases the proportion of C3-ketones

969 at low temperatures very sharply. This increase is accounted for by the decrease in the

970 proportion of monohydric alcohols in the liquid. For this $\mathrm{W} / \mathrm{m}_{\text {lactose }}$ ratio, an increase in

971 the temperature results in a substantial reduction in the proportion of this family of

972 compounds in the liquid, which accounts for the increase observed in the proportion of 973 monohydric alcohols. 
975 The effect of the pressure on the relative amount of C3-ketones strongly depends on the

976 temperature and lactose concentration. The effect of the pressure is minimal between

977200 and $220^{\circ} \mathrm{C}$, while significant variations occur between 220 and $240{ }^{\circ} \mathrm{C}$. When a 1

978 wt.\% lactose solution is used, an increase in pressure from 38 to 50 bar results in an

979 increase and a decrease in the proportion of $\mathrm{C} 3-\mathrm{ketones}$ for $\mathrm{W} / \mathrm{m}_{\text {lactose }}$ ratios of 10 and

$98040 \mathrm{~g}$ catalyst min/g lactose, respectively, between 220 and $240{ }^{\circ} \mathrm{C}$. An increase in the

981 total pressure raises the solubility of $\mathrm{H}_{2}$ in the liquid, which can compensate for the

982 decrease in the solubility of this gas with the temperature when a high amount of

983 catalyst is employed.

984

985 For a $10 \mathrm{wt} . \%$ lactose solution, the effect of the pressure depends on the $\mathrm{W} / \mathrm{m}_{\text {lactose }}$ ratio.

986 For $10 \mathrm{~g}$ catalyst $\mathrm{min} / \mathrm{g}$ lactose, an increase in the pressure from 38 to 50 bar does not

987 significantly modify the proportion of C3-ketones in the liquid. Conversely, for $40 \mathrm{~g}$

988 catalyst $\mathrm{min} / \mathrm{g}$ lactose, this increase in pressure increases the proportion of C3-ketones

989 in the liquid very sharply between 200 and $230{ }^{\circ} \mathrm{C}$. The chemical analysis of the liquid

990 reveals that this increase is accounted for by a sharp increase in 1-hydroxypropan-2-one.

991 For concentrated lactose solutions, route C is favoured over route A and B. However, an

992 increase in the $\mathrm{W} / \mathrm{m}_{\text {lactose }}$ ratio can promote the isomerisation of glucose and galactose to

993 fructose and the posterior retro-aldol reaction [27, 29], thus increasing the presence in

994 the liquid of initial products obtained from route $\mathrm{A}$. In addition, a high $\mathrm{W} / \mathrm{m}_{\text {lactose }}$ ratio

995 produces a greater spread of condensation and cross-polymerisation reactions from the

996 furan compounds obtained via route $\mathrm{C}[27,28,31,33]$.

998 The proportion of C4-ketones and cyclic-ketones in the liquid phase is lower than the 
999

1000

1001

1002

1003

1004

1005

1006

1007

1008

1009

1010

1011

1012

1013

1014

1015

1016

1017

1018

1019 from 10 to $40 \mathrm{~g}$ catalyst $\mathrm{min} / \mathrm{g}$ lactose reduces the relative amount of C4-ketones in the 1020 liquid.

relative amount of C3-ketones. 2-butanone-3-hydroxy, 1-hydroxy-2-butanone and 2,3butanedione, which are obtained from the dehydration/hydrogenation of erythritol (route B), are the most abundant C4-ketones in the liquid. The effect of the temperature on the relative amount of $\mathrm{C} 4$ ketones depends on the pressure and the concentration of lactose. At 38 bar, the effect of the temperature depends on the concentration of lactose and the $\mathrm{W} / \mathrm{m}_{\text {lactose }}$ ratio. For a $1 \mathrm{wt} . \%$ lactose solution and using $10 \mathrm{~g}$ catalyst $\mathrm{min} / \mathrm{g}$ lactose, the proportion of $\mathrm{C} 4$ ketones at low temperatures is negligible, and an increase in temperature from 200 to $240{ }^{\circ} \mathrm{C}$ leads to a substantial increase in the proportion of C4-ketones. The decrease in the $\mathrm{H}_{2}$ solubility with temperature, decreasing the proliferation of hydrogenation reactions [25] of C4-ketones to alcohols, might be responsible for this increase in the proportion of C4-ketones. Conversely, an increase in the $\mathrm{W} / \mathrm{m}_{\text {lactose }}$ ratio up to $40 \mathrm{~g}$ catalyst $\mathrm{min} / \mathrm{g}$ lactose increases the proportion of $\mathrm{C} 4$ ketones at low temperature very sharply as the presence of a catalyst favours retro-aldol reactions [30]; thus increasing the presence of liquid products obtained via route B in the liquid. For this latter ratio, an increase in temperature decreases the proportion of C4-ketones between 200 and $220^{\circ} \mathrm{C}$. A further increase in temperature up to $240{ }^{\circ} \mathrm{C}$ leads to a substantial increase in the proportion of C4-ketones. At low temperature, an increase in the temperature kinetically favours hydrogenation reactions, while a further increase in temperature decreases the $\mathrm{H}_{2}$ solubility in water, thus hindering hydrogenation reactions [25]. Between 220 and $240{ }^{\circ} \mathrm{C}$ an increase in the $\mathrm{W} / \mathrm{m}_{\text {lactose }}$ ratio gatalyst min/g lactose reduces the relative amount of $\mathrm{C} 4-\mathrm{ketones} \mathrm{in} \mathrm{the}$

1021

1022 At 50 bar and using a $\mathrm{W} / \mathrm{m}_{\text {lactose }}$ ratio of $10 \mathrm{~g}$ catalyst $\mathrm{min} / \mathrm{g}$ lactose, the effect of the 1023 temperature on the relative amount of C4-ketones in the liquid has a similar evolution 
1024 regardless of the lactose concentration. The proportion of C4-ketones increases when

1025 increasing the temperature from 200 to $220^{\circ} \mathrm{C}$, while a further increase in temperature up to $240{ }^{\circ} \mathrm{C}$ results in a decrease in the proportion of C4-ketones. High pressure

1027 promotes retro-aldol reactions in hot compressed water [66]. Therefore at 50 bar, an

1028 increase in temperature increases the proportion of C4-ketones in the liquid, which are

1029 obtained through route B due to the greater spread of glucose/galactose decomposition

1030 via reatro-aldol reactions at high pressure. Conversely, for $40 \mathrm{~g}$ catalyst $\mathrm{min} / \mathrm{g}$ lactose

1031 the effect of the temperature depends on the concentration of lactose. When feeding a 1

1032 wt.\% lactose solution, the concentration of C4-ketones decreases with temperature,

1033 while for a $10 \mathrm{wt} . \%$ solution, an increase takes places as the temperature increases from

1034200 to $240{ }^{\circ} \mathrm{C}$. For a low lactose concentration the catalyst favours hydrogenation

1035 reactions [25], which leads to a decrease in the proportion of C4-ketones. Conversely,

1036 for a concentrated lactose solution, route $\mathrm{C}$ prevails over routes $\mathrm{A}$ and $\mathrm{B}[27,28,31$,

1037 33]. Therefore, an increase in temperature might shift the retro-aldol reactions [66],

1038 which results in a liquid with a higher concentration of initial products obtained via

1039 route $\mathrm{B}$. At this pressure (50 bar), an increase in the $\mathrm{W} / \mathrm{m}_{\text {lactose }}$ ratio from 10 to $40 \mathrm{~g}$

1040 catalyst/min leads to a decrease in the proportion of C4-ketones regardless of the lactose

1041 concentration, as the catalyst favours the advancement of route B towards liquid end

1042 products.

1044 An increase in the pressure for a $1 \mathrm{wt} . \%$ lactose solution has two different effects

1045 depending on the $\mathrm{W} / \mathrm{m}_{\text {lactose }}$ ratio. When a low amount of catalyst is used, an increase in

1046 pressure from 38 to 50 bar increases and decreases the proportion of C4-ketones

1047 between 200 and $230{ }^{\circ} \mathrm{C}$ and between 230 and $240{ }^{\circ} \mathrm{C}$, respectively. This is the

1048 consequence of two developments. High pressure promotes retro-aldol reactions in hot 
1049 compressed water [66]. In addition, their subsequent transformation to end liquids is not

1050 favoured due to the low amount of catalyst, which globally results in an increase in the

1051 amount of $\mathrm{C} 4-\mathrm{ketones}$ in the liquid. For a $\mathrm{W} / \mathrm{m}_{\text {lactose }}$ ratio of $40 \mathrm{~g}$ catalyst $\mathrm{min} / \mathrm{g}$ lactose,

1052 the same increase in pressure does not provoke great differences in the proportion of

1053 C4-ketones; the proportion slightly decreases between 200 and $240{ }^{\circ} \mathrm{C}$. For a 10 wt.\%

1054 lactose solution, this increase in pressure leads to a decrease in the proportion of C4-

1055 ketones between $200-215^{\circ} \mathrm{C}$ and $225-240{ }^{\circ} \mathrm{C}$; the effect of the pressure being negligible

1056 from 215 to $225^{\circ} \mathrm{C}$. For a $10 \mathrm{wt} . \%$ lactose solution, route $\mathrm{C}$ is favoured over routes A

1057 and B [27, 28, 31, 33], which can explain the decay observed between 225 and $240{ }^{\circ} \mathrm{C}$.

1058

1059 Cyclopentanone, 2-hydroxy-3-methyl-2-cyclopenten-1-one and 2-methyl-2-

1060 cyclopenten-1-one are responsible for the variations observed in the proportion of cyclic

1061 ketones during the first hour of reaction. These ketones are obtained from the

1062 hydrogenation of different liquid intermediates obtained through the decomposition of

1063 5-hydroxymethyl-2-furancarboxaldehyde, which is obtained from glucose/galactose

1064 dehydration (route C). The effect of the temperature depends on the pressure. On the

1065 one hand, at 38 bar and regardless of the $\mathrm{W} / \mathrm{m}_{\text {lactose }}$ ratio and lactose concentration, the

1066 temperature does not significantly influence the proportion of cyclic ketones between

1067200 and $220{ }^{\circ} \mathrm{C}$, while an increase in the relative amount of this family of ketones

1068 occurs as the temperature increases from 220 to $240{ }^{\circ} \mathrm{C}$. The decrease in the $\mathrm{H}_{2}$

1069 solubility with temperature might be responsible for the increase observed in this family

1070 of compounds, as this $\mathrm{H}_{2}$ limitation stops the advancement of the reaction in the liquid

1071 phase towards end products obtained through route C. In addition, high temperatures

1072 favour route $\mathrm{C}$ over routes $\mathrm{A}$ and $\mathrm{B}[27,28,31,33]$, which accounts for the increase in

1073 this family of compounds and the decreases observed in the proportions of carboxylic 
1074 acids and monohydric alcohols. At this pressure (38 bar), an increase in the $\mathrm{W} / \mathrm{m}_{\text {lactose }}$

1075 ratio from 10 to $40 \mathrm{~g}$ catalyst $\mathrm{min} / \mathrm{g}$ lactose increases the concentration of cyclic ketones

1076 in the liquid. The $\mathrm{W} / \mathrm{m}_{\text {lactose }}$ ratio does not significantly modify the proportion of cyclic

1077 ketones in the liquid for a diluted lactose solution. However, the higher the lactose

1078 concentration, the greater is the impact of the $\mathrm{W} / \mathrm{m}_{\text {lactose }}$ ratio on the proportion of this

1079 family of ketones.

1080

1081 On the other hand, at 50 bar the effect of the temperature depends on the $\mathrm{W} / \mathrm{m}_{\text {lactose }}$ ratio and lactose concentration. For a 1 wt.\% lactose solution, the proportion of cyclic

1083 ketones sharply decreases when increasing the temperature from 200 to $220^{\circ} \mathrm{C}$ and a

1084 liquid free of cyclic ketones is obtained between 220 and $240{ }^{\circ} \mathrm{C}$. For a low $\mathrm{W} / \mathrm{m}_{\text {lactose }}$ 1085 ratio this decrease accounts for the increase in the proportion of C3-ketones, while for a 1086 high $\mathrm{W} / \mathrm{m}_{\text {lactose }}$ ratio the sharp increase in the relative amount of furans in the liquid is 1087 responsible for the decrease in the proportion of cyclic ketones. For a $10 \mathrm{wt} . \%$ lactose solution two different trends are observed depending on the $\mathrm{W} / \mathrm{m}_{\text {lactose }}$ ratio. Between

1089200 and $220^{\circ} \mathrm{C}$, the proportion of cyclic ketones drops when increasing the temperature 1090 for $10 \mathrm{~g}$ catalyst $\mathrm{min} / \mathrm{g}$ lactose. Within this temperature interval the proportion of cyclic 1091 ketones is negligible for a $\mathrm{W} / \mathrm{m}_{\text {lactose }}$ ratio of $40 \mathrm{~g}$ catalyst $\mathrm{min} / \mathrm{g}$ lactose. Between 220 and $240{ }^{\circ} \mathrm{C}$, the $\mathrm{W} / \mathrm{m}_{\text {lactose }}$ ratio does not influence the proportion of cyclic ketones, and an increase in the relative amount of cyclic ketones occurs as the reaction temperature 1094 increases regardless of the $\mathrm{W} / \mathrm{m}_{\text {lactose }}$ ratio. The increase observed in the CC gas between 1095220 and $240{ }^{\circ} \mathrm{C}$ might be responsible for this development. An increase in temperature 1096 favours the evolution of the intermediate liquid compounds obtained from route A and 1097 B towards gases [25], thus increasing the proportion of liquids obtained from route C. 1098 This transformation is favoured at high pressure [25]. In addition, the decrease in the $\mathrm{H}_{2}$ 
1099 solubility with temperature might be responsible for the increase observed in this family

1100 of compounds.

1101

1102 The effect of the pressure depends on the concentration of lactose, the temperature and

1103 the $\mathrm{W} / \mathrm{m}_{\text {lactose }}$ ratio. When a diluted lactose solution ( $\left.1 \mathrm{wt} . \%\right)$ is fed, an increase in

1104 pressure from 38 to 50 bar increases the proportion of cyclic ketones between 200 and

$1105220{ }^{\circ} \mathrm{C}$ and reduces their relative amount between 220 and $240{ }^{\circ} \mathrm{C}$, regardless of the

$1106 \mathrm{~W} / \mathrm{m}_{\text {lactose }}$ ratio. At low temperatures route $\mathrm{C}$ is not favoured, and an increase in the

1107 pressure increases the partial pressure of $\mathrm{H}_{2}$, which promotes hydrogenation reactions to

1108 produce cyclic ketones. Conversely, between 220 and $240{ }^{\circ} \mathrm{C}$ an increase in pressure

1109 favours the formation of C3-ketones and furans. When a $10 \mathrm{wt} \%$ lactose solution is fed,

1110 the effect of the pressure is only significant between 200 and $220^{\circ} \mathrm{C}$, an interval under

1111 which two different evolutions are observed depending on the $\mathrm{W} / \mathrm{m}_{\text {lactose }}$ ratio. For $10 \mathrm{~g}$

1112 catalyst $\mathrm{min} / \mathrm{g}$ lactose, the pressure does not greatly influence the proportion of cyclic

1113 ketones in the liquid, while for $40 \mathrm{~g}$ catalyst $\mathrm{min} / \mathrm{g}$ lactose this increase in pressure

1114 results in a decrease in the proportion of this family of ketones in the liquid product.

1115

1116 3.3.5 Furans

1117 Furanic compounds, mainly 5-hydroxymethil-2-furancarboxaldehyde, 5-methyl-2-

1118 furancarboxaldehyde and furfural, are obtained from the dehydration of glucose and

1119 galactose via route C. The proportion of this family of compounds in the liquid is

1120 relatively low. Exceptionally, the proportion of furans in the liquid dramatically

1121 increases with temperature at high pressure and employing a high $\mathrm{W} / \mathrm{m}_{\text {lactose }}$ ratio for a

1122 diluted lactose solution. 
1123 The effect of the temperature on the relative amount of furans strongly depends on the

1124 pressure. At 38 bar, the proportion of furans in the liquid is very low. For $10 \mathrm{~g}$ catalyst

$1125 \mathrm{~min} / \mathrm{g}$ lactose, an increase in the temperature from 200 to $220^{\circ} \mathrm{C}$ slightly increases their

1126 proportion in the liquid, while a further increase in the temperature up to $240{ }^{\circ} \mathrm{C}$ leads to

1127 a decrease in the relative amount of this family of compounds. Between 220 and $240{ }^{\circ} \mathrm{C}$

1128 the CC liq decreases and the CC sol increases very sharply as high temperatures

1129 promote the polymerisation and aldol-condensation reactions of furans [27, 28, 31, 33].

1130 At this pressure an increase from 10 to $40 \mathrm{~g}$ catalyst $\mathrm{min} / \mathrm{g}$ lactose reduces the

1131 proportion of furans regardless of the lactose concentration for the whole temperature

1132 interval considered, probably due to the greater spread of polymerisation and

1133 condensation reactions from furans [27, 28, 31,33] which might help the advancement

1134 of the reactions occurring via route $\mathrm{C}$.

1135

1136 At 50 bar, the concentration of furans in the liquid depends on the lactose concentration

1137 and the $\mathrm{W} / \mathrm{m}_{\text {lactose }}$ ratio. When a low amount of catalyst is used, the proportion of furans

1138 in the liquid is very low and the effect of the temperature is very weak. Conversely, an

1139 increase in the $\mathrm{W} / \mathrm{m}_{\text {lactose }}$ ratio has a great impact on the proportion of furans when

1140 diluted lactose solutions are used. Specifically, for a $1 \mathrm{wt} . \%$ lactose solution and $40 \mathrm{~g}$

1141 catalyst $\mathrm{min} / \mathrm{g}$ lactose, an increase in temperature from 200 to $240{ }^{\circ} \mathrm{C}$ increases the

1142 proportion of furans very sharply. This increase in the temperature also increases the

$1143 \mathrm{CC}$ sol as described above, suggesting that under these operating conditions the glucose

1144 and galactose dehydration is favoured, thus increasing the amount of liquids produced

1145 via route $\mathrm{C}$. An increase in the concentration of lactose in the solution can potentiate the

1146 condensation and polymerisation of furans, thus decreasing their relative amount in the

1147 liquid $[27,28,31,33]$. As a result, a negligible concentration of furans is obtained with 
a $10 \mathrm{wt} . \%$ lactose solution using $40 \mathrm{~g}$ catalyst $\mathrm{min} / \mathrm{g}$ lactose.

1150 The effect of the pressure depends on the lactose concentration and $\mathrm{W} / \mathrm{m}_{\text {lactose }}$ ratio.

1151 When a $\mathrm{W} / \mathrm{m}_{\text {lactose }}$ ratio of $10 \mathrm{~g}$ catalyst $\mathrm{min} / \mathrm{g}$ lactose is used, an increase in pressure

1152 from 38 to 50 bar reduces the proportion of furans regardless of the lactose

1153 concentration. An increase in the system pressure favours the advancement of the

1154 reactions leading to the formation of end products [25]. Conversely, an increase in the

$1155 \mathrm{~W} / \mathrm{m}_{\text {lactose }}$ ratio modifies the effect of the pressure. The proportion of furans augments

1156 when the $\mathrm{W} / \mathrm{m}_{\text {lactose }}$ ratio increases and decreases when increasing the concentration of

1157 lactose in the solution.

1158

\section{3.4 Prediction of optimal operating conditions within the range of study}

1160 Optimal conditions for gas and liquid production were sought for this process, making 1161 use of the experimental models developed. The predicted $\mathrm{R}^{2}$ of all the models is higher than 0.90 , allowing their use for prediction purposes. Four different optimisations were

1163 carried out. The first aims at the production of a gas with a high $\mathrm{H}_{2}$ content, and

1164 therefore comprises the maximisation of the $\mathrm{CC}$ gas and the relative amount of $\mathrm{H}_{2}$ in the

1165 gas. The second, third and fourth seek to maximise the production of alcohols

1166 (monohydric and polyhydric alcohols), ketones and furans, respectively. Therefore, the

1167 CC liq and the proportion of each family of liquids were maximised. In addition, the CC

1168 sol was minimised for all the optimisations. To meet these objectives, a solution that

1169 strikes a compromise between the optimum values for all the response variables was

1170 sought. To do this, a relative importance (from 1 to 5) was given to each of the

1171 objectives in order to come up with the solution that satisfies all the criteria. To globally 
1172 maximise gas and liquid production, a relative importance of 5 was assigned to the CC

1173 gas and CC liq, while a relative importance of 3 was given to the properties of the gas or

1174 liquid (vol. $\mathrm{H}_{2}$ and relative amount of each family of compound) and to the

1175 minimisation of the $\mathrm{CC}$ sol in all cases. Table 1 lists the optimisation results.

1176

1177 Table 1. Theoretical optimisation: Objectives, optimum values for the operating 1178 variables and optimised values for some responses

\begin{tabular}{|c|c|c|c|c|c|c|c|c|c|c|c|c|}
\hline Opt & Variable/s maximised & $\begin{array}{c}\mathrm{T} \\
\left({ }^{\circ} \mathrm{C}\right)\end{array}$ & $\begin{array}{c}\mathrm{P} \\
\text { (bar) }\end{array}$ & $\begin{array}{c}\text { [Lactose] } \\
\text { (wt.\%) }\end{array}$ & $\begin{array}{c}\mathrm{W} / \mathrm{m}_{\text {lactose }} \\
\left(\mathrm{g}_{\text {cat }} \mathrm{min} / \mathrm{g}_{\text {lactose }}\right)\end{array}$ & $\begin{array}{c}\text { CC gas } \\
(\%)\end{array}$ & $\begin{array}{c}\text { CC liq } \\
(\%)\end{array}$ & $\begin{array}{c}\text { CC sol } \\
(\%)\end{array}$ & $\begin{array}{c}\mathrm{H}_{2} \\
\text { (vol.\%) }\end{array}$ & $\begin{array}{c}\text { Alcohols } \\
(\%)\end{array}$ & $\begin{array}{c}\text { C3-ketones } \\
(\%)\end{array}$ & $\begin{array}{c}\text { Furans } \\
(\%)\end{array}$ \\
\hline 1 & CC gas, $\mathrm{H}_{2}$ (vol.\%) & 240 & 50 & 10 & 40 & 32 & 36 & 31 & 44 & 48 & 6 & 0 \\
\hline 3 & $\mathrm{CC}$ liq (C3-ketones) & 240 & 50 & 1 & 10 & 10 & 93 & 0 & 29 & 1 & 98 & 0 \\
\hline 4 & CC liq, (Furans \%) & 224 & 48 & 1 & 40 & 18 & 74 & 4 & 24 & 48 & 7 & 16 \\
\hline
\end{tabular}

1179

1180 Taking these restrictions into account, optimisation 1 predicts a possible optimum for

$1181 \mathrm{H}_{2}$ production at the highest values of the temperature, pressure, lactose concentration

1182 and $\mathrm{W} / \mathrm{m}_{\text {lactose }}$ ratio used in this work. Under these conditions $4 \mathrm{~mol} \mathrm{H}_{2} / \mathrm{mol}$ lactose is

1183 produced. This $\mathrm{H}_{2}$ yield is similar to that obtained in anaerobic fermentation (4 mol

$1184 \mathrm{H}_{2} / \mathrm{mol}$ lactose) and anaerobic fermentation plus photo-fermentation with L-malic acid

1185 (2-10 $\mathrm{mol} \mathrm{H}_{2} / \mathrm{mol}$ lactose), but lower than the $\mathrm{H}_{2}$ yield obtained during the catalytic

1186 steam reforming of lactose $\left(16 \mathrm{~mol} \mathrm{H}_{2} / \mathrm{mol}\right.$ lactose $)$ [67]. The production of value-added

1187 liquids (optimisations 2, 3 and 4) is favoured when feeding a diluted lactose solution (1

1188 wt.\%). Specifically, optimisation 2 indicates that the production of alcohols is

1189 preferential at medium temperature and medium pressure, using a low $\mathrm{W} / \mathrm{m}_{\text {lactose }}$ ratio.

1190 Under these conditions the proportions of monohydric and polyhydric alcohols in the

1191 liquid are 26 and 17\%, respectively. Optimisation 3 predicts a selective production of

1192 C3-ketones at high temperature and pressure, using a low amount of catalyst. Under

1193 these conditions, the hydrogen solubility in the liquid is relatively low. This hinders 
1194 hydrogenation reactions, thus increasing the proportion of C3-ketones in the liquid.

1195 Optimisation 4 predicts a maximum for the proportion of furans at medium temperature 1196 and high pressure using a high $\mathrm{W} / \mathrm{m}_{\text {lactose }}$ ratio.

\section{Conclusions}

1199 Aqueous phase reforming turned out to be a highly customisable process for the

1200 valorisation of lactose, the major organic constituent of cheese whey, for the production 1201 of either gas or liquid value-added chemicals. The operating variables exert a significant influence on the global results of the aqueous phase reforming (carbon converted into gas, liquid and solid products) as well as on the composition of the gas and liquid

1204 phases. The gas phase is composed of $\mathrm{H}_{2}, \mathrm{CO}_{2}, \mathrm{CO}$ and $\mathrm{CH}_{4}$. The liquid phase consisted 1205 of a mixture of aldehydes, carboxylic acids, monohydric alcohols, polyhydric-alcohols, 1206 C3, C4 and cyclic-ketones and furans. The optimisation of the process revealed that an 1207 elevated temperature and a high pressure favour gas production when using a high $1208 \mathrm{~W} / \mathrm{m}_{\text {lactose }}$ ratio and a concentrated lactose solution. Liquid production is favoured at 1209 high temperature using a diluted lactose solution and a low $\mathrm{W} / \mathrm{m}_{\text {lactose }}$ ratio. An elevated 1210 temperature and a high $\mathrm{W} / \mathrm{m}_{\text {lactose }}$ ratio favour solid production due to the proliferation 1211 of condensation and polymerisation reactions.

\section{Acknowledgements}

1214 The authors wish to express their gratitude to the Aragon Government (GPT group), the 1215 European Social Fund and the Spanish MINECO (projects ENE2010-18985 and 1216 ENE2013-41523-R) for providing financial support. In addition, Javier Remón Núñez 1217 would like to express his gratitude to the Spanish MINECO for the FPI grant awarded 
1221 [1] F. Carvalho, A.R. Prazeres, J. Rivas. Cheese whey wastewater: characterization and treatment. The Science of the Total Environment. 445-446 (2013) 385-96.

1223 [2] R.R. de Souza, R. Bergamasco, S.C. da Costa, X. Feng, S.H.B. Faria, M.L. Gimenes.

1224 Recovery and purification of lactose from whey. Chemical Engineering and Processing: Process

1225 Intensification. 49 (2010) 1137-43.

1226 [3] A.R. Prazeres, F. Carvalho, J. Rivas. Cheese whey management: a review. Journal of 1227 environmental management. 110 (2012) 48-68.

1228 [4] M.I.G. Siso. The biotechnological utilization of cheese whey: A review. Bioresource 1229 Technology. 57 (1996) 1-11.

1230 [5] O. Díaz, C.D. Pereira, A. Cobos. Functional properties of ovine whey protein concentrates produced by membrane technology after clarification of cheese manufacture by-products. Food Hydrocolloids. 18 (2004) 601-10.

[6] D. Mišún, L. Čurda, P. Jelen. Batch and continuous hydrolysis of ovine whey proteins. Small Ruminant Research. 79 (2008) 51-6.

[7] G. Guven, A. Perendeci, A. Tanyolac. Electrochemical treatment of deproteinated whey wastewater and optimization of treatment conditions with response surface methodology. Journal of Hazardous Materials. 157 (2008) 69-78.

[8] S. Ozmihci, F. Kargi. Ethanol production from cheese whey powder solution in a packed column bioreactor at different hydraulic residence times. Biochemical Engineering Journal. 42 (2008) 180-5.

[9] G. Vidal, A. Carvalho, R. Méndez, J.M. Lema. Influence of the content in fats and proteins on the anaerobic biodegradability of dairy wastewaters. Bioresource Technology. 74 (2000) 231-9.

[10] J.R. Kar, J.E. Hallsworth, R.S. Singhal. Fermentative production of glycine betaine and trehalose from acid whey using Actinopolyspora halophila (MTCC 263). Environmental Technology and Innovation. 3 (2015) 68-76.

[11] A.J. Mawson. Bioconversions for whey utilization and waste abatement. Bioresource Technology. 47 (1994) 195-203.

[12] S. Sansonetti, S. Curcio, V. Calabrò, G. Iorio. Bio-ethanol production by fermentation of ricotta cheese whey as an effective alternative non-vegetable source. Biomass and Bioenergy. 33 (2009) 1687-92.

1252 [13] D.L. King, L. Zhang, G. Xia, A.M. Karim, D.J. Heldebrant, X. Wang, et al. Aqueous phase reforming of glycerol for hydrogen production over Pt-Re supported on carbon. Applied Catalysis B: Environmental. 99 (2010) 206-13.

[14] Y.-C. Lin. Catalytic valorization of glycerol to hydrogen and syngas. International Journal of Hydrogen Energy. 38 (2013) 2678-700.

[15] M. Metsoviti, K. Paraskevaidi, A. Koutinas, A.-P. Zeng, S. Papanikolaou. Production of 1,3-propanediol, 2,3-butanediol and ethanol by a newly isolated Klebsiella oxytoca strain growing on biodiesel-derived glycerol based media. Process Biochemistry. 47 (2012) 1872-82. [16] Z. Yuan, J. Wang, L. Wang, W. Xie, P. Chen, Z. Hou, et al. Biodiesel derived glycerol hydrogenolysis to 1,2-propanediol on $\mathrm{Cu} / \mathrm{MgO}$ catalysts. Bioresource Technology. 101 (2010) 7099-103.

[17] J.W. Shabaker, G.W. Huber, J.A. Dumesic. Aqueous-phase reforming of oxygenated Catalysts. Proccedings of the 12 Aiche Anual Meeting. (2012). 
1267 [19] T. Jiang, T. Wang, L. Ma, Y. Li, Q. Zhang, X. Zhang. Investigation on the xylitol aqueousphase reforming performance for pentane production over Pt/HZSM-5 and Ni/HZSM-5 catalysts. Applied Energy. 90 (2012) 51-7.

[20] A.V. Kirilin, A.V. Tokarev, H. Manyar, C. Hardacre, T. Salmi, J.P. Mikkola, et al. Aqueous phase reforming of xylitol over Pt-Re bimetallic catalyst: Effect of the Re addition. Catalysis Today. 223 (2014) 97-107. [21] J. Xi, Q. Xia, Y. Shao, D. Ding, P. Yang, X. Liu, et al. Production of hexane from sorbitol in aqueous medium over $\mathrm{Pt} / \mathrm{NbOPO}_{4}$ catalyst. Applied Catalysis B: Environmental. 181 (2016) 699-706.

[22] F. Aiouache, L. McAleer, Q. Gan, A.a.H. Al-Muhtaseb, M.N. Ahmad. Path lumping kinetic model for aqueous phase reforming of sorbitol. Applied Catalysis A: General. 466 (2013) 240-55.

[23] A.V. Kirilin, A.V. Tokarev, L.M. Kustov, T. Salmi, J.P. Mikkola, D.Y. Murzin. Aqueous phase reforming of xylitol and sorbitol: Comparison and influence of substrate structure. Applied Catalysis A: General. 435-436 (2012) 172-80.

[24] L.I. Godina, A.V. Kirilin, A.V. Tokarev, D.Y. Murzin. Aqueous phase reforming of industrially relevant sugar alcohols with different chiralities. ACS Catalysis. 5 (2015) 29893005 .

[25] J. Remón, J.R. Giménez, A. Valiente, L. García, J. Arauzo. Production of gaseous and liquid chemicals by aqueous phase reforming of crude glycerol: Influence of operating conditions on the process. Energy Conversion and Management. 110 (2016) 90-112. [26] A. Valiente, J.A. Medrano, M. Oliva, J. Ruiz, L. Garcia, J. Arauzo. Bioenergy II: Hydrogen Production by Aqueous-Phase Reforming. International Journal of Chemical Reactor Engineering. 8 (2010).

[27] J. Tuteja, S. Nishimura, K. Ebitani. One-Pot Synthesis of Furans from Various Saccharides Using a Combination of Solid Acid and Base Catalysts. Bulletin of the Chemical Society of Japan. 85 (2012) 275-81.

[28] J.N. Chheda, J.A. Dumesic. An overview of dehydration, aldol-condensation and hydrogenation processes for production of liquid alkanes from biomass-derived carbohydrates. Catalysis Today. 123 (2007) 59-70.

[29] G. Liang, L. He, H. Cheng, W. Li, X. Li, C. Zhang, et al. The hydrogenation/dehydrogenation activity of supported Ni catalysts and their effect on hexitols selectivity in hydrolytic hydrogenation of cellulose. Journal of Catalysis. 309 (2014) 468-76. [30] C. Liu, C. Zhang, S. Hao, S. Sun, K. Liu, J. Xu, et al. WOx modified Cu/Al2O3 as a highperformance catalyst for the hydrogenolysis of glucose to 1,2-propanediol. Catalysis Today. 261 (2016) 116-27.

[31] G.W. Huber, J.A. Dumesic. An overview of aqueous-phase catalytic processes for production of hydrogen and alkanes in a biorefinery. Catalysis Today. 111 (2006) 119-32. [32] J. Lee, Y. Xu, G.W. Huber. High-throughput screening of monometallic catalysts for aqueous-phase hydrogenation of biomass-derived oxygenates. Applied Catalysis B:

Environmental. 140-141 (2013) 98-107.

[33] D.W. Rackemann, J.P. Bartley, W.O.S. Doherty. Methanesulfonic acid-catalyzed conversion of glucose and xylose mixtures to levulinic acid and furfural. Industrial Crops and Products. 52 (2014) 46-57.

[34] X. Hu, G. Lu. Investigation of the steam reforming of a series of model compounds derived from bio-oil for hydrogen production. Applied Catalysis B: Environmental. 88 (2009) 376-85. [35] M. Marquevich, S. Czernik, E. Chornet, D. Montané. Hydrogen from Biomass: Steam Reforming of Model Compounds of Fast-Pyrolysis Oil. Energy and Fuels. 13 (1999) 1160-6. [36] I. Gandarias, P.L. Arias, J. Requies, M.B. Güemez, J.L.G. Fierro. Hydrogenolysis of glycerol to propanediols over a Pt/ASA catalyst: The role of acid and metal sites on product selectivity and the reaction mechanism. Applied Catalysis B: Environmental. 97 (2010) 248-56. [37] A. Wawrzetz, B. Peng, A. Hrabar, A. Jentys, A.A. Lemonidou, J.A. Lercher. Towards understanding the bifunctional hydrodeoxygenation and aqueous phase reforming of glycerol. Journal of Catalysis. 269 (2010) 411-20. 
Re surface properties with reaction pathways for the aqueous-phase reforming of glycerol. Journal of Catalysis. 287 (2012) 37-43.

[39] K. Yan, G. Wu, T. Lafleur, C. Jarvis. Production, properties and catalytic hydrogenation of furfural to fuel additives and value-added chemicals. Renewable and Sustainable Energy Reviews. 38 (2014) 663-76.

[40] M.E. Zakrzewska, E. Bogel-Łukasik, R. Bogel-Łukasik. Ionic Liquid-Mediated Formation of 5-Hydroxymethylfurfural-A promising biomass-derived building block. Chemical Reviews. 111 (2011) 397-417.

[41] M.J. Taylor, L.J. Durndell, M.A. Isaacs, C.M.A. Parlett, K. Wilson, A.F. Lee, et al. Highly selective hydrogenation of furfural over supported Pt nanoparticles under mild conditions. Applied Catalysis B: Environmental. 180 (2016) 580-5.

[42] Z. Xinghua, W. Tiejun, M. Longlong, W. Chuangzhi. Aqueous-phase catalytic process for production of pentane from furfural over nickel-based catalysts. Fuel. 89 (2010) 2697-702.

[43] R.R. Davda, J.W. Shabaker, G.W. Huber, R.D. Cortright, J.A. Dumesic. A review of catalytic issues and process conditions for renewable hydrogen and alkanes by aqueous-phase reforming of oxygenated hydrocarbons over supported metal catalysts. Applied Catalysis B: Environmental. 56 (2005) 171-86.

[44] Z. Abu El-Rub, E.A. Bramer, G. Brem. Experimental comparison of biomass chars with other catalysts for tar reduction. Fuel. 87 (2008) 2243-52.

[45] N.B. Klinghoffer, M.J. Castaldi, A. Nzihou. Influence of char composition and inorganics on catalytic activity of char from biomass gasification. Fuel. 157 (2015) 37-47.

[46] Z. Min, P. Yimsiri, M. Asadullah, S. Zhang, C.-Z. Li. Catalytic reforming of tar during gasification. Part II. Char as a catalyst or as a catalyst support for tar reforming. Fuel. 90 (2011) 2545-52.

[47] T.Y. Mun, J.O. Kim, J.W. Kim, J.S. Kim. Influence of operation conditions and additives on the development of producer gas and tar reduction in air gasification of construction woody wastes using a two-stage gasifier. Bioresource Technology. 102 (2011) 7196-203.

[48] T. Oike, S. Kudo, H. Yang, J. Tahara, H.-S. Kim, R. Koto, et al. Sequential pyrolysis and potassium-catalyzed steam-oxygen gasification of woody biomass in a continuous two-stage reactor. Energy and Fuels. 28 (2014) 6407-18.

[49] N. Striūgas, K. Zakarauskas, G. Stravinskas, V. Grigaitienè. Comparison of steam reforming and partial oxidation of biomass pyrolysis tars over activated carbon derived from waste tire. Catalysis Today. 196 (2012) 67-74.

[50] D. Wang, W. Yuan, W. Ji. Char and char-supported nickel catalysts for secondary syngas cleanup and conditioning. Applied Energy. 88 (2011) 1656-63.

[51] T. Jiang, Q. Zhang, T.-J. Wang, Q. Zhang, L.-L. Ma. High yield of pentane production by aqueous-phase reforming of xylitol over Ni/HZSM-5 and Ni/MCM22 catalysts. Energy Conversion and Management. 59 (2012) 58-65.

[52] N. Luo, X. Fu, F. Cao, T. Xiao, P.P. Edwards. Glycerol aqueous phase reforming for hydrogen generation over Pt catalyst - Effect of catalyst composition and reaction conditions. Fuel. 87 (2008) 3483-9.

[53] H.-D. Kim, H.J. Park, T.-W. Kim, K.-E. Jeong, H.-J. Chae, S.-Y. Jeong, et al. The effect of support and reaction conditions on aqueous phase reforming of polyol over supported Pt-Re bimetallic catalysts. Catalysis Today. 185 (2012) 73-80.

[54] D. Roy, B. Subramaniam, R.V. Chaudhari. Aqueous phase hydrogenolysis of glycerol to 1,2-propanediol without external hydrogen addition. Catalysis Today. 156 (2010) 31-7. [55] G. Wen, Y. Xu, H. Ma, Z. Xu, Z. Tian. Production of hydrogen by aqueous-phase reforming of glycerol. International Journal of Hydrogen Energy. 33 (2008) 6657-66. [56] M. El Doukkali, A. Iriondo, J.F. Cambra, I. Gandarias, L. Jalowiecki-Duhamel, F. Dumeignil, et al. Deactivation study of the $\mathrm{Pt}$ and/or Ni-based $\gamma-\mathrm{Al}_{2} \mathrm{O}_{3}$ catalysts used in the aqueous phase reforming of glycerol for $\mathrm{H}_{2}$ production. Applied Catalysis A: General. 472 (2014) 80-91. 
1374 [57] H. Chen, Y. Ding, N.T. Cong, B. Dou, V. Dupont, M. Ghadiri, et al. A comparative study 1375 on hydrogen production from steam-glycerol reforming: thermodynamics and experimental.

1376 Renewable Energy. 36 (2011) 779-88.

1377 [58] B. Dou, Y. Song, C. Wang, H. Chen, Y. Xu. Hydrogen production from catalytic steam

1378 reforming of biodiesel byproduct glycerol: Issues and challenges. Renewable and Sustainable

1379 Energy Reviews. 30 (2014) 950-60.

1380 [59] K. Kamonsuangkasem, S. Therdthianwong, A. Therdthianwong. Hydrogen production

1381 from yellow glycerol via catalytic oxidative steam reforming. Fuel Processing Technology. 106

1382 (2013) 695-703.

1383 [60] J.M. Silva, M.A. Soria, L.M. Madeira. Challenges and strategies for optimization of

1384 glycerol steam reforming process. Renewable and Sustainable Energy Reviews. 42 (2015)

1385 1187-213.

1386 [61] M. Slinn, K. Kendall, C. Mallon, J. Andrews. Steam reforming of biodiesel by-product to

1387 make renewable hydrogen. Bioresource Technology. 99 (2008) 5851-8.

1388 [62] S.N. Delgado, D. Yap, L. Vivier, C. Especel. Influence of the nature of the support on the

1389 catalytic properties of Pt-based catalysts for hydrogenolysis of glycerol. Journal of Molecular

1390 Catalysis A: Chemical. 367 (2013) 89-98.

1391 [63] S.P. Verevkin, V.N. Emel'yanenko, E.N. Stepurko, R.V. Ralys, D.H. Zaitsau, A. Stark.

1392 Biomass-Derived Platform Chemicals: Thermodynamic Studies on the Conversion of 5-

1393 hydroxymethylfurfural into bulk intermediates. Industrial and Engineering Chemistry Research.

139448 (2009) 10087-93.

1395 [64] R.L. Manfro, A.F. da Costa, N.F.P. Ribeiro, M.M.V.M. Souza. Hydrogen production by

1396 aqueous-phase reforming of glycerol over nickel catalysts supported on $\mathrm{CeO}_{2}$. Fuel Processing

1397 Technology. 92 (2011) 330-5.

1398 [65] D.Ö. Özgür, B.Z. Uysal. Hydrogen production by aqueous phase catalytic reforming of 1399 glycerine. Biomass and Bioenergy. 35 (2011) 822-6.

1400 [66] M. Sasaki, K. Goto, K. Tajima, T. Adschiri, K. Arai. Rapid and selective retro-aldol 1401 condensation of glucose to glycolaldehyde in supercritical water. Green Chemistry. 4 (2002) $1402 \quad 285-7$.

1403 [67] J. Remón, M. Laseca, L. García, J. Arauzo. Hydrogen production from cheese whey by 1404 catalytic steam reforming: Preliminary study using lactose as a model compound. Energy

1405 Conversion and Management. 114 (2016) 122-41.

1406 


\section{SUPLEMENTARY MATERIAL}

FIGURES

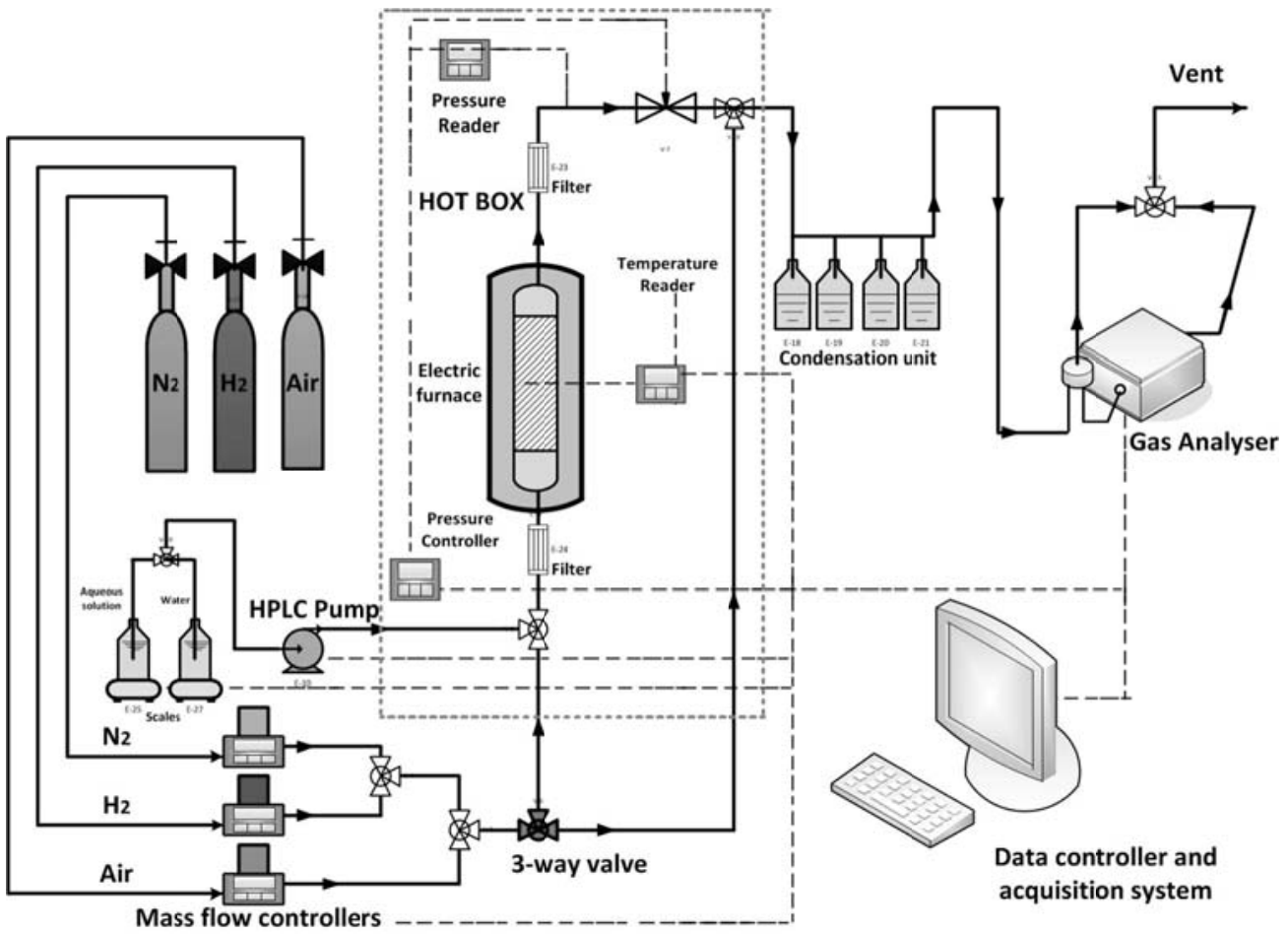

Figure S1. Schematic diagram of the aqueous phase reforming experimental rig. 

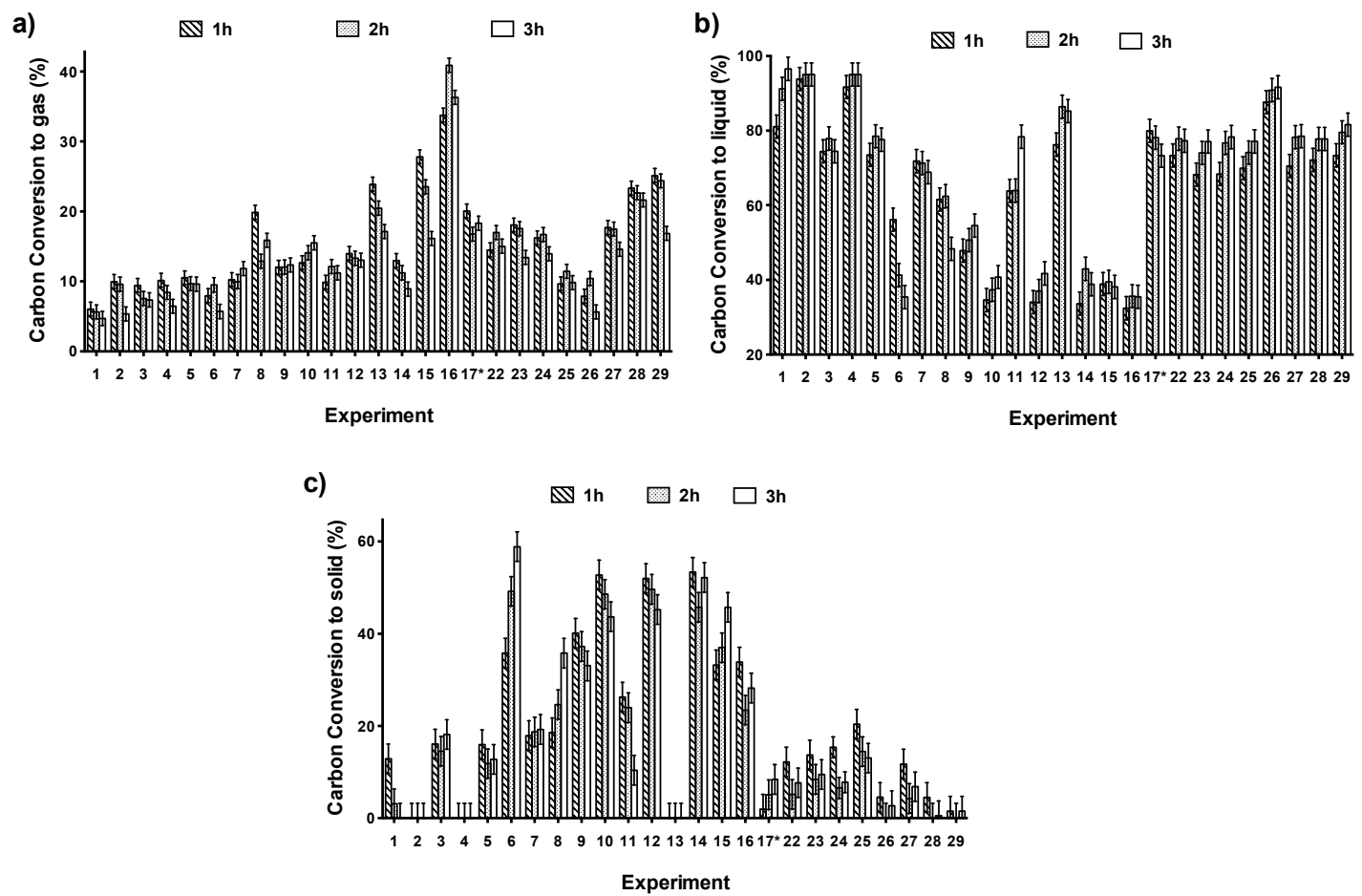

Figure S2. Carbon conversion to gas (a), liquid (b) and solid (c) obtained during the APR experiments. Results are presented as the overall values obtained every 60 minutes and expressed as mean \pm 0.5 Fisher LSD intervals with $95 \%$ confidence.

a)

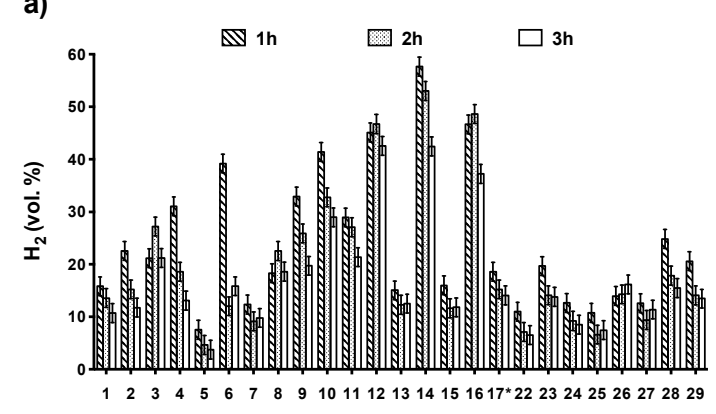

c)

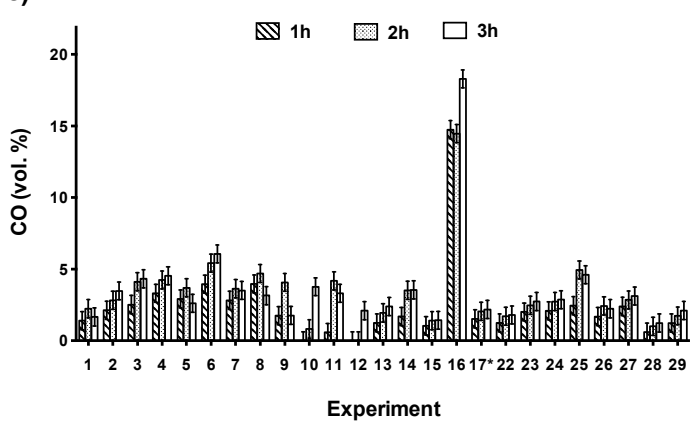

b)

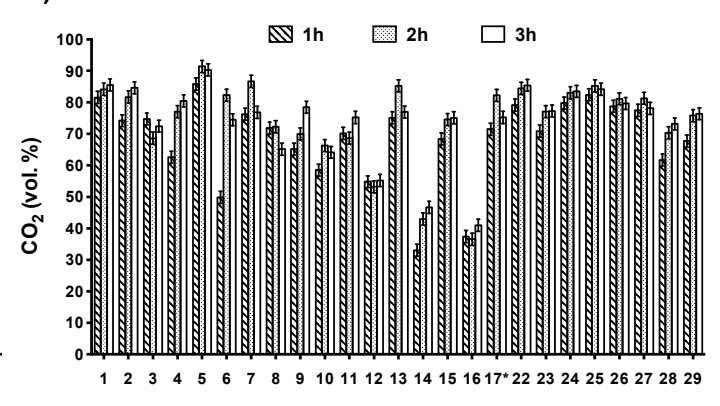

d)

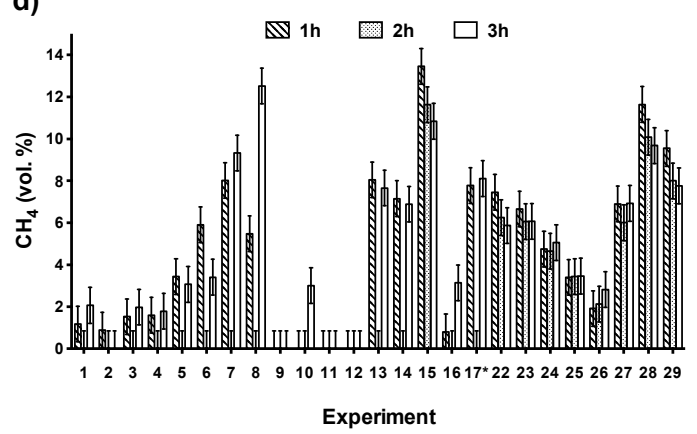

Figure S3. Relative amounts (vol.\%) of $\mathrm{H}_{2}(\mathrm{a}), \mathrm{CO}_{2}$ (b) $\mathrm{CO}$ (c) and $\mathrm{CH}_{4}(\mathrm{~d})$ in the gas obtained during the APR experiments. Results are presented as the overall values obtained every 60 minutes and expressed as mean \pm 0.5 Fisher LSD intervals with $95 \%$ confidence. 

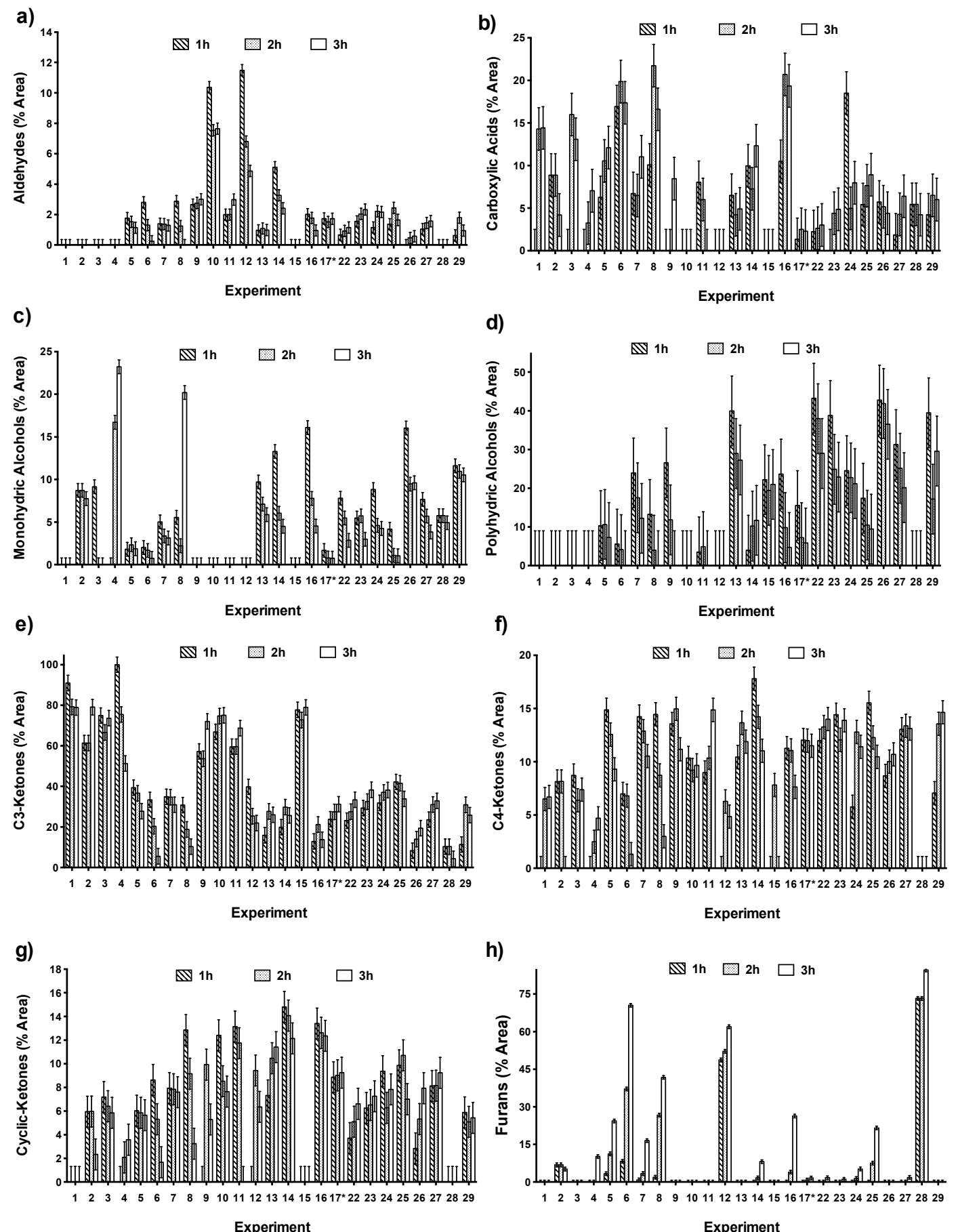

Figure S4. Proportions (\% chromatographic area) of aldehydes (a), carboxylic acids (b), monohydric alcohols (c), polyhydric alcohols (d), C3-ketones (e), C4-ketones (f), cyclic ketones (g) and furans (h) in the liquid obtained during the APR experiments. Results are presented as the overall values obtained every 60 minutes and expressed as mean \pm 0.5 Fisher LSD intervals with $95 \%$ confidence. 


\section{TABLES}

Table S1. Response variables. Definitions and analytical techniques used in their

determination.

\begin{tabular}{|c|c|c|}
\hline Product & Response variable & $\begin{array}{c}\text { Analytical method } \\
\end{array}$ \\
\hline Gas & $\begin{array}{c}\text { CC gas }(\%)=\frac{\mathrm{C} \text { in the gas }(\mathrm{g})}{\mathrm{C} \text { fed }(\mathrm{g})} 100 \\
\text { Composition (vol. \%) }=\frac{\text { mol of each gas }}{\text { total mol of gas }} 100\end{array}$ & $\begin{array}{c}\text { Micro Gas Chromatograph (Micro GC). } \mathrm{N}_{2} \text { as } \\
\text { internal standard } \\
\text { Online analyses }\end{array}$ \\
\hline \multirow{4}{*}{ Liquid } & CC liq $(\%)=\frac{C \text { in the liquid products }(\mathrm{g})}{\mathrm{C} \text { fed }(\mathrm{g})} 100$ & Total Organic Carbon (TOC). \\
\hline & Composition $($ area $\%)=\frac{\text { area of each compound }}{\text { total area }} 100$ & GC-MS (Gas Chromatography-Mass Spectrometry) \\
\hline & $\mathrm{X}$ lactose $(\%)=\frac{\text { lactose fed }(\mathrm{g})-\text { lactose in the liquid }(\mathrm{g})}{100}$ & HPLC (High Performance Liquid Chromatography) \\
\hline & $\begin{array}{ll}\text { lactose fed }(\mathrm{g}) \\
\end{array}$ & Offline analyses \\
\hline Solid & CC sol $(\%)=100-$ CC gas $(\%)-$ CC liq* $(\%)$ & \\
\hline
\end{tabular}

Table S2. Operating conditions employed in the experiments

\begin{tabular}{|c|c|c|c|c|c|c|c|c|}
\hline \multirow[t]{2}{*}{ Run } & \multicolumn{2}{|c|}{$\begin{array}{l}\text { Lactose } \\
\text { (wt.\%) }\end{array}$} & \multicolumn{2}{|c|}{$\begin{array}{l}\begin{array}{l}\text { Pressure } \\
\text { (bar) }\end{array} \\
\end{array}$} & \multicolumn{2}{|c|}{$\begin{array}{c}\text { Temperature } \\
\left({ }^{\circ} \mathrm{C}\right)\end{array}$} & \multicolumn{2}{|c|}{$\begin{array}{c}\text { Wcatalyst } / \mathrm{m}_{\text {lactose }} \\
\text { (g cat } \mathrm{min} / \mathrm{g} \text { lactose) }\end{array}$} \\
\hline & Actual & codec & actual & codec & actual & codec & Actual & codec \\
\hline 1 & 1 & -1 & 38 & -1 & 200 & -1 & 10 & -1 \\
\hline 2 & 1 & -1 & 38 & -1 & 240 & 1 & 10 & -1 \\
\hline 3 & 1 & -1 & 50 & 1 & 200 & -1 & 10 & -1 \\
\hline 4 & 1 & -1 & 50 & 1 & 240 & 1 & 10 & -1 \\
\hline 5 & 10 & 1 & 38 & -1 & 200 & -1 & 10 & -1 \\
\hline 6 & 10 & 1 & 38 & -1 & 240 & 1 & 10 & -1 \\
\hline 7 & 10 & 1 & 50 & 1 & 200 & -1 & 10 & -1 \\
\hline 8 & 10 & 1 & 50 & 1 & 240 & 1 & 10 & -1 \\
\hline 9 & 1 & -1 & 38 & -1 & 200 & -1 & 40 & 1 \\
\hline 10 & 1 & -1 & 38 & -1 & 240 & 1 & 40 & 1 \\
\hline 11 & 1 & -1 & 50 & 1 & 200 & -1 & 40 & 1 \\
\hline 12 & 1 & -1 & 50 & 1 & 240 & 1 & 40 & 1 \\
\hline 13 & 10 & 1 & 38 & -1 & 200 & -1 & 40 & 1 \\
\hline 14 & 10 & 1 & 38 & -1 & 240 & 1 & 40 & 1 \\
\hline 15 & 10 & 1 & 50 & 1 & 200 & -1 & 40 & 1 \\
\hline 16 & 10 & 1 & 50 & 1 & 240 & 1 & 40 & 1 \\
\hline $17 *(17,18,19,20,21)$ & 5.5 & 0 & 44 & 0 & 220 & 0 & 25 & 0 \\
\hline 22 & 5.5 & 0 & 44 & 0 & 200 & -1 & 25 & 0 \\
\hline 23 & 5.5 & 0 & 44 & 0 & 240 & 1 & 25 & 0 \\
\hline 24 & 5.5 & 0 & 38 & -1 & 220 & 0 & 25 & 0 \\
\hline 25 & 5.5 & 0 & 50 & 1 & 220 & 0 & 25 & 0 \\
\hline 26 & 1 & -1 & 44 & 0 & 220 & 0 & 25 & 0 \\
\hline 27 & 10 & 1 & 44 & 0 & 220 & 0 & 25 & 0 \\
\hline 28 & 5.5 & 0 & 44 & 0 & 220 & 0 & 10 & -1 \\
\hline 29 & 5.5 & 0 & 44 & 0 & 220 & 0 & 40 & 1 \\
\hline
\end{tabular}


Table S3. Relative influence of the operating conditions on the CC gas, CC liq and CC sol according to the ANOVA analysis for the first hour of reaction.

\begin{tabular}{|c|c|c|c|c|c|c|c|c|c|c|c|c|c|c|c|c|c|c|c|c|c|c|c|c|c|c|}
\hline & $\mathrm{R}^{2}$ & Indep. & $\mathrm{T}$ & $\mathrm{P}$ & C & W & TP & $\mathrm{TC}$ & TW & PC & PW & $\mathrm{CW}$ & $\mathrm{T}^{2}$ & $\mathrm{P}^{2}$ & $\mathrm{C}^{2}$ & $\mathrm{~W}^{2}$ & TPC & TPW & TCW & PCW & $\mathrm{T}^{2} \mathrm{P}$ & $\mathrm{T}^{2} \mathrm{C}$ & $\mathrm{T}^{2} \mathrm{~W}$ & $\mathrm{TP}^{2}$ & $\mathrm{~T}^{2} \mathrm{P}^{2}$ & TPCW \\
\hline \multirow{2}{*}{$\begin{array}{c}\mathrm{CC} \text { gas } \\
(\%)\end{array}$} & \multirow{2}{*}{0.95} & \multirow[t]{2}{*}{20.07} & \multirow[t]{2}{*}{ n.s } & -3.28 & 4.04 & \multirow[t]{2}{*}{ n.s } & 1.83 & \multirow[t]{2}{*}{$\mathrm{n} . \mathrm{s}$} & \multirow[t]{2}{*}{ n.s } & 2.10 & \multirow[t]{2}{*}{ n.s } & 2.30 & -3.79 & -7.12 & -7.29 & 4.17 & 1.90 & \multirow[t]{2}{*}{ n.s } & \multirow[t]{2}{*}{ n.s } & 1.09 & 5.72 & \multirow[t]{2}{*}{ n.s } & 3.93 & \multirow[t]{2}{*}{ n.s } & 8.40 & \multirow[t]{2}{*}{ n.s } \\
\hline & & & & (6) & (14) & & (6) & & & (7) & & (8) & (2) & (7) & (10) & (6) & (6) & & & (4) & (6) & & (13) & & (4) & \\
\hline \multirow{2}{*}{$\begin{array}{l}\text { CC liq } \\
(\%)\end{array}$} & \multirow[t]{2}{*}{0.97} & \multirow[t]{2}{*}{78.28} & \multirow[t]{2}{*}{ n.s } & \multirow[t]{2}{*}{$\mathrm{n} . \mathrm{s}$} & -5.23 & \multirow[t]{2}{*}{ n.s } & \multirow[t]{2}{*}{ n.s } & -3.97 & -5.91 & -2.60 & \multirow[t]{2}{*}{$\mathrm{n} . \mathrm{s}$} & 4.92 & -8.12 & -9.73 & \multirow[t]{2}{*}{ n.s } & \multirow[t]{2}{*}{ n.s } & 3.45 & \multirow[t]{2}{*}{ n.s } & 3.22 & -4.15 & \multirow[t]{2}{*}{ n.s } & \multirow[t]{2}{*}{ n.s } & -15.17 & -5.61 & \multirow[t]{2}{*}{ n.s } & 3.13 \\
\hline & & & & & (8) & & & (6) & (8) & (4) & & (7) & (14) & (6) & & & (6) & & (4) & (6) & & & (21) & (8) & & (4) \\
\hline $\begin{array}{c}\text { CC sol } \\
(\%)\end{array}$ & 0.97 & 3.74 & n.s & $\mathrm{n} . \mathrm{s}$ & n.s & n.s & $\begin{array}{c}-3.88 \\
(6)\end{array}$ & $\begin{array}{c}4.07 \\
(6)\end{array}$ & $\begin{array}{l}6.3 \\
(9)\end{array}$ & n.s & n.s & $\begin{array}{l}-6.87 \\
(10)\end{array}$ & $\begin{array}{l}8.48 \\
(17)\end{array}$ & $\begin{array}{c}13.42 \\
(9)\end{array}$ & n.s & n.s & $\begin{array}{c}-5.12 \\
\text { (7) }\end{array}$ & n.s & $-2-12$ & $\begin{array}{l}2.93 \\
(4)\end{array}$ & n.s & n.s & $\begin{array}{c}10.90 \\
(16)\end{array}$ & $\begin{array}{c}5.24 \\
(8)\end{array}$ & n.s & $\begin{array}{c}-3.12 \\
(5)\end{array}$ \\
\hline
\end{tabular}

n.s: Non significant with $95 \%$ confidence

Response $=$ Indep.+ Coefficient $\mathrm{T} \cdot \mathrm{T}+$ Coefficient $\mathrm{P} \cdot \mathrm{P}+$ Coefficient $\mathrm{C} \cdot \mathrm{C}+$ Coefficient $\mathrm{W} \cdot \mathrm{W}+$ Coefficient TC $\cdot \mathrm{T} \cdot \mathrm{C}+$ Coefficient TW $\cdot \mathrm{T} \cdot \mathrm{W}+\mathrm{Coefficient} \mathrm{PC} \cdot \mathrm{P} \cdot \mathrm{C}+\mathrm{Coefficient} \mathrm{PW} \cdot \mathrm{P} \cdot \mathrm{W}+\mathrm{Coefficient} \mathrm{CW} \cdot \mathrm{C} \cdot \mathrm{W}+$ Coefficient $\mathrm{T}^{2} \cdot \mathrm{T}^{2}+$ Coefficient $\mathrm{P}^{2} \cdot \mathrm{P}^{2}+$ Coefficient $\mathrm{C}^{2} \cdot \mathrm{C}^{2}+$ Coefficient $\mathrm{W}^{2} \cdot \mathrm{W}^{2}+$ Coefficient TPC $\cdot T \cdot P \cdot C+$ Coefficient TPW $\cdot \mathrm{T} \cdot \mathrm{P} \cdot \mathrm{W}+\mathrm{Coefficient} \mathrm{TCW} \cdot \mathrm{T} \cdot \mathrm{C} \cdot \mathrm{W}+\mathrm{Coefficient} \mathrm{PCW} \cdot \mathrm{P} \cdot \mathrm{C} \cdot \mathrm{W}+\mathrm{Coefficient}$ $\mathrm{T}^{2} \mathrm{P} \cdot \mathrm{T}^{2} \cdot \mathrm{P}+$ Coefficient $\mathrm{T}^{2} \mathrm{C} \cdot \mathrm{T}^{2} \cdot \mathrm{C}+$ Coefficient $\mathrm{T}^{2} \mathrm{~W} \cdot \mathrm{T}^{2} \cdot \mathrm{W}+$ Coefficient $\mathrm{T} \mathrm{P}^{2} \cdot \mathrm{T} \cdot \mathrm{P}^{2}+$ Coefficient TPCW $\mathrm{T} \cdot \mathrm{P} \cdot \mathrm{C} \cdot \mathrm{W}$

Numbers in brackets indicate the percentage Pareto influence of each factor on the response variable. Pareto values represent the percentage of the orthogonal estimated total value. 
Table S4. Relative influence of the operating conditions on the volumetric composition of the gas according to the ANOVA analysis for the first hour of reaction.

\begin{tabular}{|c|c|c|c|c|c|c|c|c|c|c|c|c|c|c|c|c|c|c|c|c|c|c|c|c|c|c|}
\hline & $\mathrm{R}^{2}$ & Ind. & $\mathrm{T}$ & $\mathrm{P}$ & $\mathrm{C}$ & W & $\mathrm{TP}$ & $\mathrm{TC}$ & TW & PC & PW & $\mathrm{CW}$ & $\mathrm{T}^{2}$ & $\mathrm{P}^{2}$ & $\mathrm{C}^{2}$ & $\mathrm{~W}^{2}$ & TPC & TPW & TCW & PCW & $\mathrm{T}^{2} \mathrm{P}$ & $\mathrm{T}^{2} \mathrm{C}$ & $\mathrm{T}^{2} \mathrm{~W}$ & $\mathrm{TP}^{2}$ & $\mathrm{~T}^{2} \mathrm{P}^{2}$ & TPCW \\
\hline $\mathrm{H}_{2} \quad($ vol.\%) & 0.95 & 16.69 & $\begin{array}{l}4.34 \\
(20)\end{array}$ & n.s & n.s & n.s & $\begin{array}{c}-1.67 \\
(4)\end{array}$ & $\begin{array}{c}4.35 \\
(9)\end{array}$ & $\begin{array}{c}2.73 \\
(6)\end{array}$ & $\begin{array}{c}-2.48 \\
(5)\end{array}$ & n.s & n.s & n.s & $\begin{array}{c}-4.98 \\
(1)\end{array}$ & n.s & $\begin{array}{l}6.03 \\
(17)\end{array}$ & $\begin{array}{c}-3.03 \\
(7)\end{array}$ & n.s & $\begin{array}{c}1.72 \\
(4)\end{array}$ & n.s & n.s & $\begin{array}{c}-1.64 \\
(4)\end{array}$ & $\begin{array}{l}7.23 \\
(16)\end{array}$ & $\begin{array}{l}5.17 \\
(4)\end{array}$ & $\begin{array}{c}10.5 \\
(5)\end{array}$ & n.s \\
\hline $\mathrm{CO}_{2}$ (vol.\%) & 1 & 71.51 & $\begin{array}{l}-4.13 \\
(16)\end{array}$ & $\begin{array}{l}\mathrm{n} . \mathrm{s} \\
\mathrm{n} . \mathrm{s}\end{array}$ & $\begin{array}{l}\text { n.s } \\
\text { n.s }\end{array}$ & $\begin{array}{l}3.01 \\
(11)\end{array}$ & $\begin{array}{l}1.82 \\
\text { (3) }\end{array}$ & $\begin{array}{c}-4.50 \\
(7)\end{array}$ & $\begin{array}{c}-2.20 \\
\text { n.s }\end{array}$ & $\begin{array}{l}1.70 \\
(3)\end{array}$ & n.s & $\begin{array}{c}-1.59 \\
(3)\end{array}$ & $\begin{array}{c}3.53 \\
(8)\end{array}$ & $\begin{array}{c}9.60 \\
(3)\end{array}$ & $\begin{array}{c}6.64 \\
(2)\end{array}$ & $\begin{array}{c}-6.77 \\
(8)\end{array}$ & $\begin{array}{l}\mathrm{n} . \mathrm{s} \\
(6)\end{array}$ & $\begin{array}{c}-1.53 \\
(3)\end{array}$ & $\begin{array}{c}-1.88 \\
(3)\end{array}$ & $\begin{array}{c}-2.16 \\
(4)\end{array}$ & $\begin{array}{l}\text { n.s } \\
\text { n.s }\end{array}$ & $\begin{array}{c}-2.76 \\
(5)\end{array}$ & $\begin{array}{c}-5.54 \\
(6)\end{array}$ & $\begin{array}{c}-5.54 \\
(3)\end{array}$ & $\begin{array}{c}-19.52 \\
(4)\end{array}$ & $\begin{array}{c}1.04 \\
(2)\end{array}$ \\
\hline CO (vol.\%) & 0.97 & 1.54 & n.s & n.s & n.s & n.s & $\begin{array}{c}0.91 \\
(7)\end{array}$ & $\begin{array}{c}1.07 \\
(9)\end{array}$ & $\begin{array}{c}0.50 \\
(4)\end{array}$ & $\begin{array}{c}0.73 \\
(6)\end{array}$ & 0.59 & $\begin{array}{l}0.76 \\
(6)\end{array}$ & n.s & $\begin{array}{c}1.17 \\
(6)\end{array}$ & n.s & n.s & $\begin{array}{l}0.76 \\
(6)\end{array}$ & $\begin{array}{c}0.89 \\
(7)\end{array}$ & $\begin{array}{c}0.99 \\
(8)\end{array}$ & $\begin{array}{c}1.03 \\
(8)\end{array}$ & $\begin{array}{l}0.87 \\
(7)\end{array}$ & $\begin{array}{l}1.29 \\
(11)\end{array}$ & n.s & $\begin{array}{c}0.97 \\
(8)\end{array}$ & n.s & $\begin{array}{l}0.75 \\
(6)\end{array}$ \\
\hline $\mathrm{CH}_{4}$ (vol.\%) & 0.93 & 7.62 & n.s & n.s & $\begin{array}{l}2.89 \\
(22)\end{array}$ & n.s & $\begin{array}{c}-1.03 \\
(7)\end{array}$ & $\begin{array}{c}-0.84 \\
(6)\end{array}$ & $\begin{array}{c}-0.83 \\
(6)\end{array}$ & $\mathrm{n} . \mathrm{s}$ & n.s & $\begin{array}{c}0.74 \\
(5)\end{array}$ & n.s & $\begin{array}{c}-3.62 \\
(8)\end{array}$ & $\begin{array}{l}-3.29 \\
(18)\end{array}$ & $\begin{array}{c}2.90 \\
(9)\end{array}$ & $\begin{array}{c}-1.07 \\
(8)\end{array}$ & $\mathrm{n} . \mathrm{s}$ & $\begin{array}{c}-0.86 \\
(6)\end{array}$ & n.s & n.s & $\mathrm{n} . \mathrm{s}$ & n.s & $\begin{array}{c}-0.87 \\
(6)\end{array}$ & n.s & $\mathrm{n} . \mathrm{s}$ \\
\hline Aldehydes (\%) & 0.94 & 1.27 & n.s & n.s & $\mathrm{n} . \mathrm{s}$ & n.s & $\mathrm{n} . \mathrm{s}$ & $\begin{array}{c}-0.53 \\
(7)\end{array}$ & $\begin{array}{l}1.30 \\
(17)\end{array}$ & n.s & n.s & $\begin{array}{r}-1.70 \\
(23)\end{array}$ & n.s & $\mathrm{n} . \mathrm{s}$ & $\mathrm{n} . \mathrm{s}$ & $\mathrm{n} . \mathrm{s}$ & $\mathrm{n} . \mathrm{s}$ & $\mathrm{n} . \mathrm{s}$ & $\begin{array}{l}-0.85 \\
(11)\end{array}$ & n.s & n.s & $\begin{array}{c}-0.60 \\
(8)\end{array}$ & $\begin{array}{l}1.61 \\
(21)\end{array}$ & 1.62 & $\begin{array}{l}1.45 \\
(13)\end{array}$ & n.s \\
\hline $\begin{array}{c}\text { Carboxylic } \\
\text { Acids (\%) }\end{array}$ & 0.93 & 4.23 & n.s & $\begin{array}{c}-6.54 \\
(5)\end{array}$ & n.s & n.s & n.s & $\begin{array}{l}2.25 \\
(12)\end{array}$ & n.s & $\begin{array}{c}-1.27 \\
(7)\end{array}$ & $\mathrm{n} . \mathrm{s}$ & $\begin{array}{c}-1.32 \\
(7)\end{array}$ & -3.11 & $\begin{array}{l}7.74 \\
(14)\end{array}$ & n.s & n.s & $\mathrm{n} . \mathrm{s}$ & $\mathrm{n} . \mathrm{s}$ & $\mathrm{n} . \mathrm{s}$ & n.s & $\begin{array}{l}6.27 \\
(11)\end{array}$ & $\begin{array}{l}3.69 \\
(20)\end{array}$ & $\mathrm{n} . \mathrm{s}$ & $\begin{array}{l}1.25 \\
(7)\end{array}$ & $\begin{array}{c}-4.18 \\
(5)\end{array}$ & $\begin{array}{l}1.40 \\
(7)\end{array}$ \\
\hline Mono-OH (\%) & 0.96 & 7.44 & n.s & $\begin{array}{c}-2.32 \\
(1)\end{array}$ & $\begin{array}{c}-4.19 \\
(9)\end{array}$ & $\begin{array}{c}0.97 \\
(5)\end{array}$ & n.s & $\begin{array}{c}1.88 \\
(8)\end{array}$ & $\begin{array}{c}1.79 \\
(8)\end{array}$ & $\mathrm{n} . \mathrm{s}$ & $\begin{array}{c}-1.37 \\
(6)\end{array}$ & $\begin{array}{l}2.06 \\
(9)\end{array}$ & n.s & $\mathrm{n} . \mathrm{s}$ & $\begin{array}{c}4.42 \\
(9)\end{array}$ & $\begin{array}{c}2.92 \\
(6)\end{array}$ & $\begin{array}{c}1.32 \\
(6)\end{array}$ & $\begin{array}{c}1.28 \\
(6)\end{array}$ & 0.67 & n.s & $\begin{array}{c}2.92 \\
(3)\end{array}$ & $\begin{array}{l}6.93 \\
(10)\end{array}$ & n.s & 0.76 & $\begin{array}{c}-10.92 \\
(11)\end{array}$ & $\mathrm{n} . \mathrm{s}$ \\
\hline Poly-OH (\%) & 0.75 & 28.31 & n.s & n.s & n.s & $\begin{array}{l}4.99 \\
(13)\end{array}$ & n.s & n.s & n.s & n.s & n.s & & $\begin{array}{c}12.71 \\
(23)\end{array}$ & n.s & n.s & n.s & n.s & $\begin{array}{l}4.16 \\
(10)\end{array}$ & n.s & n.s & $\mathrm{n} . \mathrm{s}$ & $\begin{array}{l}7.04 \\
(17)\end{array}$ & n.s & $\begin{array}{l}-4.99 \\
(12)\end{array}$ & $\begin{array}{c}-30.22 \\
(25)\end{array}$ & n.s \\
\hline $\begin{array}{c}\text { C3-Ketones } \\
(\%)\end{array}$ & 0.95 & 23.28 & n.s & n.s & n.s & $\begin{array}{l}-8.97 \\
(10)\end{array}$ & $\begin{array}{c}-3.58 \\
(4)\end{array}$ & $\begin{array}{c}-4.50 \\
(5)\end{array}$ & $\begin{array}{c}-4.50 \\
(5)\end{array}$ & $\begin{array}{l}4.11 \\
(4)\end{array}$ & $\mathrm{n} . \mathrm{s}$ & $\begin{array}{l}6.73 \\
(7)\end{array}$ & $\mathrm{n} . \mathrm{s}$ & $\begin{array}{l}13.7 \\
(18)\end{array}$ & $\mathrm{n} . \mathrm{s}$ & n.s & $\begin{array}{c}-4.78 \\
(5)\end{array}$ & $\begin{array}{c}-8.70 \\
(9)\end{array}$ & $\mathrm{n} . \mathrm{s}$ & $\begin{array}{c}5.85 \\
(6)\end{array}$ & n.s & $\begin{array}{l}-18.9 \\
(19)\end{array}$ & n.s & $\begin{array}{c}-4.38 \\
(4)\end{array}$ & $\begin{array}{c}14.95 \\
(5)\end{array}$ & n.s \\
\hline $\begin{array}{c}\text { C4-ketones } \\
(\%)\end{array}$ & 0.95 & 11.86 & n.s & $\begin{array}{c}4.88 \\
(5)\end{array}$ & 2.06 & $\begin{array}{c}-4.02 \\
(3)\end{array}$ & $\begin{array}{c}-1.14 \\
(5)\end{array}$ & $\begin{array}{l}1.0 \\
(4)\end{array}$ & $\mathrm{n} . \mathrm{s}$ & $\begin{array}{l}0.74 \\
(3)\end{array}$ & $\begin{array}{c}-1.98 \\
(8)\end{array}$ & $\begin{array}{c}-1.21 \\
(5)\end{array}$ & n.s & $\begin{array}{c}-2.48 \\
(7)\end{array}$ & n.s & n.s & $\begin{array}{l}2.65 \\
(11)\end{array}$ & $\begin{array}{l}0.91 \\
(4)\end{array}$ & $\begin{array}{l}2.85 \\
(12)\end{array}$ & $\begin{array}{c}-1.0 \\
(4)\end{array}$ & $\begin{array}{c}-6.89 \\
(9)\end{array}$ & n.s & $\begin{array}{c}3.85 \\
(5)\end{array}$ & $\mathrm{n} . \mathrm{s}$ & n.s & $\begin{array}{c}-1.43 \\
(6)\end{array}$ \\
\hline $\begin{array}{c}\text { Cyclic Ketones } \\
(\%)\end{array}$ & 0.93 & 9.08 & $\begin{array}{c}1.68 \\
(9)\end{array}$ & n.s & $\begin{array}{l}2.02 \\
(11)\end{array}$ & $\begin{array}{l}0.76 \\
(4)\end{array}$ & $\begin{array}{l}-1.98 \\
(10)\end{array}$ & $\begin{array}{l}1.82 \\
(10)\end{array}$ & $\begin{array}{c}0.79 \\
(4)\end{array}$ & n.s & $\begin{array}{c}-0.89 \\
(5)\end{array}$ & n.s & $\begin{array}{l}-4.1 \\
(2)\end{array}$ & n.s & $\begin{array}{c}-3.60 \\
(3)\end{array}$ & $\begin{array}{c}.4 .40 \\
(2)\end{array}$ & $\begin{array}{l}3.01 \\
(16)\end{array}$ & $\begin{array}{c}0.88 \\
(5)\end{array}$ & $\mathrm{n} . \mathrm{s}$ & $\begin{array}{c}-0.97 \\
(5)\end{array}$ & n.s & n.s & n.s & n.s & $\begin{array}{l}9.94 \\
(9)\end{array}$ & $\begin{array}{c}0.93 \\
(5)\end{array}$ \\
\hline Furans (\%) & 1 & 0 & n.s & n.s & n.s & $\begin{array}{c}-3.86 \\
(3)\end{array}$ & $\begin{array}{c}2.76 \\
(6) \\
\end{array}$ & $\begin{array}{c}-2.62 \\
(5)\end{array}$ & $\begin{array}{c}2.62 \\
(5)\end{array}$ & $\begin{array}{c}-3.55 \\
(7) \\
\end{array}$ & $\begin{array}{c}3.55 \\
(7)\end{array}$ & $\begin{array}{c}-3.90 \\
(8)\end{array}$ & $\mathrm{n} . \mathrm{s}$ & n.s & n.s & $\begin{array}{c}3.86 \\
(5) \\
\end{array}$ & $\begin{array}{c}-3.24 \\
(7) \\
\end{array}$ & $\begin{array}{c}-3.24 \\
(7)\end{array}$ & $\begin{array}{c}-3.38 \\
(7)\end{array}$ & $\begin{array}{c}-2.45 \\
(5) \\
\end{array}$ & $\begin{array}{c}2.45 \\
(5)\end{array}$ & $\begin{array}{c}-2.10 \\
(4)\end{array}$ & $\begin{array}{c}5.96 \\
(4)\end{array}$ & $\begin{array}{c}3.38 \\
(7)\end{array}$ & $\begin{array}{c}0.036 \\
(1)\end{array}$ & $\begin{array}{c}-2.76 \\
(6) \\
\end{array}$ \\
\hline
\end{tabular}

n.s: Non significant with $95 \%$ confidence

Response = Ind. + Coefficient T $\cdot \mathrm{T}+$ Coefficient P $\cdot \mathrm{P}+$ Coefficient $\mathrm{C} \cdot \mathrm{C}+$ Coefficient $\mathrm{W} \cdot \mathrm{W}+$ Coefficient TC $\cdot \mathrm{T} \cdot \mathrm{C}+$ Coefficient $\mathrm{TW} \cdot \mathrm{T} \cdot \mathrm{W}+\mathrm{Coefficient} \mathrm{PC} \cdot \mathrm{P} \cdot \mathrm{C}+\mathrm{Coefficient} \mathrm{PW} \cdot \mathrm{P} \cdot \mathrm{W}+\mathrm{Coefficient} \mathrm{CW} \cdot \mathrm{C} \cdot \mathrm{W}+$

Coefficient $\mathrm{T}^{2} \cdot \mathrm{T}^{2}+$ Coefficient $\mathrm{P}^{2} \cdot \mathrm{P}^{2}+$ Coefficient $\mathrm{C}^{2} \cdot \mathrm{C}^{2}+$ Coefficient $\mathrm{W}^{2} \cdot \mathrm{W}^{2}+$ Coefficient TPC$\cdot \mathrm{T} \cdot \mathrm{P} \cdot \mathrm{C}+$ Coefficient TPW$\cdot \mathrm{T} \cdot \mathrm{P} \cdot \mathrm{W}+\mathrm{Coefficient} \mathrm{TCW} \cdot \mathrm{T} \cdot \mathrm{C} \cdot \mathrm{W}+\mathrm{Coefficient} \mathrm{PCW} \cdot \mathrm{P} \cdot \mathrm{C} \cdot \mathrm{W}+\mathrm{Coefficient} \mathrm{T}^{2} \mathrm{P} \cdot \mathrm{T}^{2} \cdot \mathrm{P}+$

Coefficient $\mathrm{T}^{2} \mathrm{C} \cdot \mathrm{T}^{2} \cdot \mathrm{C}+$ Coefficient $\mathrm{T}^{2} \cdot \mathrm{W} \cdot \mathrm{T}^{2} \cdot \mathrm{W}+$ Coefficient $\mathrm{T} \cdot \mathrm{P}^{2} \cdot \mathrm{T} \cdot \mathrm{P}^{2}+$ Coefficient TPCW $\cdot \mathrm{T} \cdot \mathrm{P} \cdot \mathrm{C} \cdot \mathrm{W}$.

Numbers in brackets indicate the percentage Pareto influence of each factor on the response variable. Pareto values represent the percentage of the orthogonal estimated total value. 